GA-A15749

UC-20d

\title{
Missisp
}

\section{ASSESSMENT OF MARTENSITIC STEELS AS STRUCTURAL MATERIALS IN MAGNETIC FUSION DEVICES}

\author{
by \\ J. M. RAWLS, W. Y. K. CHEN, E. T. CHENG \\ J. A. DALESSANDRO, P. H. MILLER, S. N. \\ ROSENWASSER, and L. D. THOMPSON
}

\begin{abstract}
Prepared under
Contract DE-AT03-76ET51011

for the San Francisco Operations Office

Department of Energy
\end{abstract}

JANUARY 1980 


\section{DISCLAIMER}

This report was prepared as an account of work sponsored by an agency of the United States Government. Neither the United States Government nor any agency Thereof, nor any of their employees, makes any warranty, express or implied, or assumes any legal liability or responsibility for the accuracy, completeness, or usefulness of any information, apparatus, product, or process disclosed, or represents that its use would not infringe privately owned rights. Reference herein to any specific commercial product, process, or service by trade name, trademark, manufacturer, or otherwise does not necessarily constitute or imply its endorsement, recommendation, or favoring by the United States Government or any agency thereof. The views and opinions of authors expressed herein do not necessarily state or reflect those of the United States Government or any agency thereof. 


\section{DISCLAIMER}

Portions of this document may be illegible in electronic image products. Images are produced from the best available original document. 


\section{NOTICE}

This report was prepared as an account of work sponsored by an agency of the United States Government. Neither the United States nor any agency thereof, nor any of their employees, makes any warranty, expressed or implied. or assumes any legal liability or iespunsiluilily for any thurd party's use or the results of such use of any information, apparatus, product or process disclosed in this report, or represents that its use by such third party would not infringe privately owned rights.

Printed in the United States of America Available from

National Technical Information Service

U.S. Department of Commerce

5285 Port Royal Road

Springfield, Virginia 22161

NTIS Price Codes: Printed Copy A04; Microfiche Copy A01 
GA-A15749

UC-20d

\title{
ASSESSMENT OF MARTENSITIC STEELS AS STRUCTURAL MATERIALS IN MAGNETIC FUSION DEVICES
}

\author{
by \\ J. M. RAWLS, W. Y. K. CHEN, E. T. CHENG \\ J. A. DALESSANDRO, P. H. MILLER, S. N. \\ ROSENWASSER, and L. D. THOMPSON
}

\begin{abstract}
Prepared under
Contract DE-AT03-76ET51011

for the San Francisco Operations Office

Department of Energy
\end{abstract}

\section{GENERAL ATOMIC PROJECT 3235.881.001 \\ JANUARY 1980}

\section{GENERAL ATOMIC COMPANY}


CONTENTS

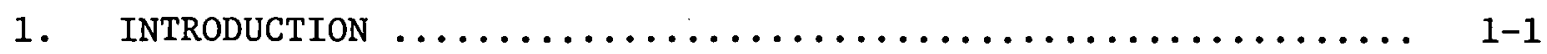

2. PROPERTIES AND BEHAVIOR OF MARTENSITIC ALLOYS PERTINENT

TO FUSION APPLICATIONS $\ldots \ldots \ldots \ldots \ldots \ldots \ldots \ldots \ldots \ldots \ldots \ldots \ldots$ 2-1

2.1. Mechanical Behavior .................... 2-2

2.2. Radiation Damage $\ldots \ldots \ldots \ldots \ldots \ldots \ldots \ldots \ldots \ldots \ldots \ldots$ 2-5

2.3. Application Experience ................... 2-5

2.4. Metallurgical Performance Evaluation of HT-9 ....... 2-7

2.5. Identification of Key Issues and Major Data

Requirements ......................... 2-10

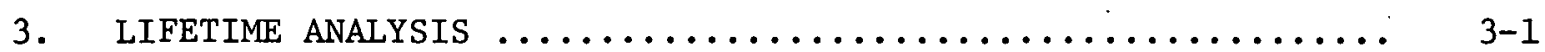

3.1. Model Employed.$\ldots \ldots \ldots \ldots \ldots \ldots \ldots \ldots \ldots \ldots \ldots \ldots$ 3-1

3.2. Results and Discussion $\ldots \ldots \ldots \ldots \ldots \ldots \ldots \ldots \ldots \ldots$ 3-4

3.3. Implications for Potential Application to ETF ...... 3-6

4. MEASUREMENT OF MAGNETIC PROPERTIES $\ldots \ldots \ldots \ldots \ldots \ldots \ldots \ldots \ldots$ 4 4 .

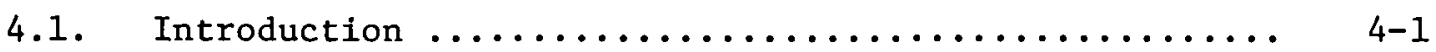

4.2. Previous Results ...................... 4-1

4.3. Current Experiments ..................... 4-2

4.4. Results ................................ $4-4$

4.5. Conclusions $\ldots \ldots \ldots \ldots \ldots \ldots \ldots \ldots \ldots \ldots \ldots \ldots \ldots$ 4-9

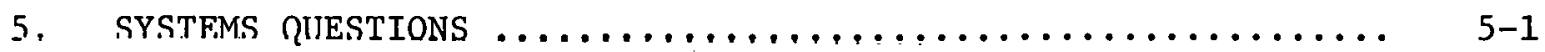

5.1. Description of Numerical Tools ............... 5-2

5.2. Magnetic Perturbations - Toroidal Fleld .......... 5-5

5.3. Magnetic Perturbations - Poloidal Field ........... 5-6

5.4. Magnetic Perturbations - Transient Analysis ........ 5-8

5.5. Magnetic Loads ...................... 5-11

5.6. Safety and Environmental Considerations .......... 5-13

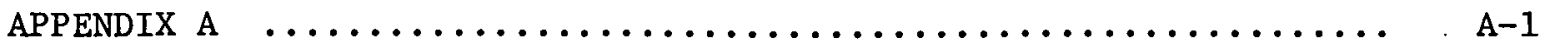


FIGURES

2-1 Minimum ultimate strength of HT-9 and other candidate alloys. 2-3

2-2 Effect of 80,000 hour, $600^{\circ} \mathrm{C}$ service exposure on HT-9 stress-rupture properties ...................... 2-8

2-3 Effect of 80,000 hour, $600^{\circ} \mathrm{C}$ service exposure on HT-9 tensile properties .......................... 2-8

2-4 Effect of 80,000 hour, $600^{\circ} \mathrm{C}$ service exposure on HT-9 impact properties .......................... 2-9

3-1 Systems l1fetime comparison of HT-9 with $20 \%$ r.w 316 for

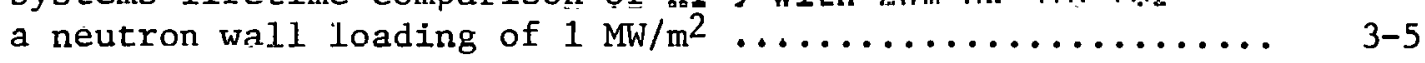

4-1 Comparison of hysteresis loops of HT-9 at $500^{\circ} \mathrm{C}$ for two different maximum primary currents ................. 4-5

4-2 Comparison of the hysteresis loops for $12 \mathrm{Cr} 1$ Mo at room temperature and a typical operating temperature in reactor

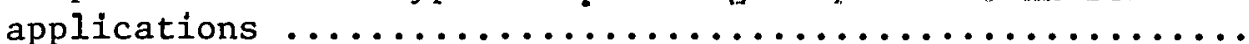

4-3 Comparison of $9 \mathrm{Cr}$ and $12 \mathrm{Cr}$ martensitic steel hysteresis

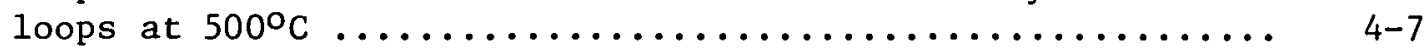

4-4 Variation in hysteresis loops with bias field ......... 4-8

4-5 Magnetic properties in a simulated tokamak environment .... 4-9

5-1 S'IARFIRE toroidai field ripple showing the effects of a ferromagnetic (FM) blanket with and without penetrations ... 5-6

5-2 S'I'ARFIRE polotdal field perturbation due to a terromagnctic blanket ...................... 5-7

5-3 Magnetic loading on the ferromagnetic blankets for the GA TNS, STARFIRE and ETF designs ................ 5-13

\section{TABLES}

2-1 Nominal composition of alloy HT-9 in weight percent ...... 2-2

2-2 Allowable 300,000 hour design stresses $\left(S_{\text {ft }}\right)$ of HT-9 and 316 based on the criteria of ASME Boiler and Pressure Vesse1 Code Case $N 47$ (elevated temperature service) ....... 2-3

2-3 Thermal stress reststance of candidate fusion alloys

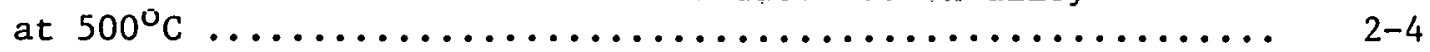

2-4 Foreign usage and performance of $9-12 \mathrm{Cr}$ steels in fossil power plants .......................... 2-6

2-5 Current data base for HT-9 and modified $9 \mathrm{Cr}-1$ Mo ....... 2-11 
4-1 Characteristics of toroidal transformers used for material evaluation ......................... 4-3

5-1 Parameters used for field perturbation and force computations 5-5

5-2 Radial body forces and equivalent inward pressures at

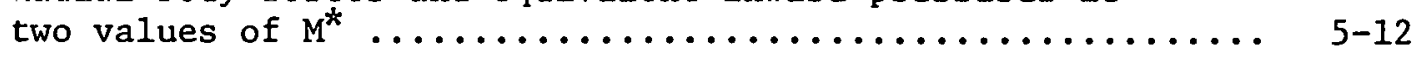

5-3 Radioactivity after shutdown in HT-9 and 316 SS-based blankets (assume $1 \mathrm{MW} / \mathrm{m}^{2}$ wall loading for 6 years) ....... 5-14

5-4 Biological hazard potential after shutdown in HT-9 and $316 \mathrm{SS}-\mathrm{structured}$ blankets (assume $1 \mathrm{MW} / \mathrm{m}^{2}$ wall loading

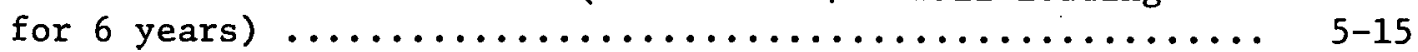

5-5 Afterheat following shutdown in HT-9 and 316 SS-based blankets ................................ 5 5-15 


\section{INTRODUCTION AND SUMMARY}

First wal1/blanket lifetime has been identified as a key issue in the ultimate commercialization of fusion power. Because of the considerable cost and time involved in first wall/blanket changeouts, the structural materials employed must exhibit long life behavior under severe operating conditions. The current U.S. program to develop materials for commercial reactors is focused on several classes of metallic materials, including austenitic stainless steels, precipitation-hardened Fe-Ni-Cr alloys, reactive metal alloys (titanium) and refractory alloys (vanadium and niobium). Recent results from fission reactor irradiation experiments in the United States and Europe suggest that another group of alloys, the Fe-Cr martensitic stainless steels, might offer the potential of significantly greater first wall/blanket lifetimes and, therefore, should be given serious consideration. This manuscript documents the results of preliminary experiments and analyses to assess the feasibility of incorporating ferromagnetic martensitic steels in fusion reactor designs and to evaluate the possible advantages of this class of material with respect to first wall/blanket lifetime.

The general class of alloys under consideration are ferritic steels containing from about 9 to 13 percent $\mathrm{Cr}$ with some small additions of various strengthening elements such as Mo. These steels are conventionally used in the normalized and tempered condition for high temperature applications and, as discussed in Section 2, can compete favorably with austenitic alloys up to about $600^{\circ} \mathrm{C}$. Although the heat treatment can result in either a tempered martensite or bainite structure, depending on the alloy and thermal treatment parameters, this general class of materlals will be referred to as "martensitic" stainless steels for simplicity. These steels have been employed successfully in such high temperature applications as steam turbines, jet engines and gas turbines. The commercial $12 \mathrm{Cr}-1 \mathrm{Mo}-0.3 \mathrm{~V}$ Sandvik alloy, HT-9, has been used in Europe for steam pipe lines and for tubes/headers in fossil-fired boilers for over ten years and is currently being considered 
for a number of thermal and fast reactor components including steam generators, recuperators, auxiliary heat exchangers and steam piping.

On the basis of irradiation test results, HT-9 was among a group of six prime advanced candidate materials identified by the National FBR Cladding/ Duct Materials development program and is in fact the only commercial candidate alloy. Because of the encouraging and rapidly expanding data base from the FBR Program, the significant application history and the current interest in the alloy, $\mathrm{H} \mathrm{T}-9$ was selected as a representative martensitic alloy for the current evaluation.

The material properties of martensitic alloys pertinent to fusion applications are summarized in Section 2, The radiation damage resistanre is discussed and the resistance to damage from cyclic fatigue and creep fatigue is shown to be superior to other candidate materials. The applications history of martensitic steels is briefly reviewed and results are presented of an evaluation of a specimen subjected to 80,000 hours of $600^{\circ} \mathrm{C}$ operation. Finally, a detailed evaluation of the known data bases for martensitic steels has been conducted in the light of fusion design requirements in order to identify the key issues that must be resolved for application in the Fngineering Test Facility.

In Section 3, a comparison of expected lifetimes is presented for tritium breeding blanket modules for $20 \%$ SW 316 stainless steel and HT-9. The lifc of the module was optimized for each material by varying the wall thickness. Maximum lifetime is obtained by trading off life governed by crack growth with that governed by maximum allowable creep strain. It is shown that HT-9 can give approximately five times greater life compared to 316 stainless steel for typical tokamak reactor operating conditions.

The magnetic properties of martensitic steels required for a thorough evaluation of the systems questions involved in their potential use in magnetic confinement devices were not known at the outset of the study. While it was known that the material responds linearly, i.e. as a paramagnet, when immersed 
in a saturating magnetic field and subjected to variations in that field, no measurements had been made of its response to time-changing fields normal to the saturating field, which is the situation in toroidal, current-carrying magnetic confinement devices.

To investigate such effects, measurements were made in a simulated tokamak environment; the results of these investigations are reported in Section 4. Hysteresis loops for a variety of ac primary currents were obtained on two samples of $12 \mathrm{Cr} 1$ Mo (HT-9) and one sample of $9 \mathrm{Cr} 2$ Mo as a function of a steady-state bias field up to 60,000 gauss over a temperature range of 25 to $550^{\circ} \mathrm{C}$. The samples were in the form of a toroidal transformer and the bias field was applied both parallel and perpendicular to the symmetry axis. The saturation inductance decreases with increasing temperatures for both materials. The materials are quite similar in magnetic behavior and they become paramagnetic when the internal magnetizing bias field is greater than 500 to 2000 oersted. The permeability for the fields arising from currents in the poloidal coils approaches unity under reactor conditions. The small departure from unity depends on the geometry and the value for the saturation induction, which is about 11,000 gauss in $12 \mathrm{Cr} 1$ Mo at $500^{\circ} \mathrm{C}$.

The properties so deduced were used as the basis of an analysis of the systems implications of using martensitic steels as a structural material in a magnetic fusion environment. The studies reported in Section 5 focus two potential problem areas: the effects on plasma performance and the impact on the mechanical design of the blanket. A 3-D field code IRON allowing the presence of saturable ferromagnetic material was developed to facilitate the investigation. This investfgation encompassed generic studies as well as specific applications to TNS, ETF, and STARFIRE designs.

One major concern in the area of plasma performance is the effect of the ferromagnetic blanket on toroidal field ripple. Results indicate that because the blanket material is highly saturated by the toroidal field, the effect of an axisymmetric blanket on toroldal field ripple is very small. Even the additional ripple produced by penctratione in the blanket such as 
neutral beam ducts was found to be insignificant. Another concern is the interaction of the ferromagnetic blanket with the plasma shaping and control system, in particular the field-shaping coils. The high level of saturation by the toroidal field is found to reduce the perturbations to only about $3 \%$ of the poloidal field. In addition, the effective permeability $\mu$ is nearly unity, so the operation of the field-shaping coils is not expected to be significantly affected. The most impartant question from the point of view of engineering impact appears to be the magnetic forces on the blanket. Results indicate that for a martensitic steel blanket in a typical reactor, the magnetic loading does not exceed the equivalent of a few atm of static pressure, which should not pose a signiticant mechanical design problem. Section 5 also substantiates the claim that martensitic steels have environmental and safety advantages over austenitic steels in fusion applications.

The conclusion of the study as a whole is that there are no major systems issues involved in the application of martensitic steels as structural materials in magnetic fusion devices. The following important characteristics relative to other candidate materials

- potentially superior radiation resistance

- favorable thermal-physical properties

- adequate structural properties to $550^{\circ} \mathrm{C}$

- desirable from a resources perspective

- improved safety and environmental features

then suggest increased emphasis on the unresolved materials questions involved in specific fusion applications. 


\section{PROPERTIES AND BEHAVIOR OF MARTENSITIC ALLOYS}

PERTINENT TO FUSION APPLICATIONS

The general class of alloys under consideration are ferritic steels containing from about 9 to 13 percent $\mathrm{Cr}$ with some small additions of carbide stabilizing and/or strengthening elements such as Mo and V. These steels are conventionally used in the normalized and tempered condition for high temperature applications (Ref, 2-1) and, as discussed below, can compete favorably with austenitic alloys up to about $600^{\circ} \mathrm{C}$. Although the heat treatment can result in either a tempered martensite or bainite structure, depending on the alloy and thermal treatment parameters, this general class of materials will be referred to as "martensitic" stainless steels for simplicity. These steels have been employed successfully in such high temperature applications as steam turbines, jet engines and gas turbines. The $12 \mathrm{Cr}-1 \mathrm{Mo}-0.3 \mathrm{~V}$ alloy type has been used commercially for high temperature applications in Europe for over ten years. The $\mathrm{W}$ containing alloy specified in Germany as DINX20CrMoWV121, Material No. 1.4935 (marketed by Sandvik in the U.S. as alloy HT-9) is currently being considered for a number of thermal and fast reactor components including steam generators, recuperators, auxiliary heat exchangers and steam piping.

On the basis of irradiation test results, HT-9 was among a group of six prime advanced candidate materials identified for detailed study in the United States National FBR Cladding/Duct Materials Development Program and is in fact the only commercial candidate alloy. Because of the encouraging and rapidly expanding data base from the FBR Program, the significant application history and the current interest in the alloy, HT-9 was selected as a representative martensitic alloy for the current evaluation. It should be noted that other alloys in this class, such as the modified $9 \mathrm{Cr}-1$ Mo material being developed for the FBR program, may eventually prove superior for fusion application, but their current data base was insufficient to assess their potential.

The nominal composition of alloy HT-9 is given in Table 2-1. For high temperature, extended time service, the alloy is usually heat treated at $1050^{\circ} \mathrm{C}$ for $0.5 \mathrm{hr}$, air cooled and then tempered at $780^{\circ} \mathrm{C}$. Although higher 
TABLE 2-1

NOMINAL COMPOSITION OF ALLOY HT-9 IN WEIGHT PERCENT

\begin{tabular}{c|c|c|c|c|c|c|c|c}
\hline Fe & $\mathrm{Cr}$ & $\mathrm{Ni}$ & $\mathrm{Mo}$ & $\mathrm{W}$ & $\mathrm{V}$ & $\mathrm{Si}$ & $\mathrm{Mn}$ & $\mathrm{C}$ \\
\hline Balance & 11.5 & 0.5 & 1.0 & 0.5 & 0.3 & 0.25 & 0.5 & 0.20 \\
\hline
\end{tabular}

strengths are obtainable in $12 \mathrm{Cr}$ steels with lower tempering temperatures, the $780^{\circ} \mathrm{C}$ treatment ensures long time stability of the tempered martensite and strengthening carbide precipitates to about $600^{\circ} \mathrm{C}$ service temperature.

\subsection{MECHANICAL BEHAVIOR}

The strength of HT- 9 is compared to that for several other candidate first wall/blanket alloys in Fig. 2-1. The variation of minimum ultimate tensile strength with temperature is plotted for HT-9 (Ref. 2-2), 20 percent cold worked 316 stainless steel (20CW316), annealed 316 stainless steel (316), Inconel 718 (Ref. 2-3), Titanium alloys Ti-6Al-4V and Ti-6Al-2 Sn-4 $\mathrm{Zr}-2$ Mo (Ref. 2-4), Vanadium alloy V-20 Ti (Ref. 2-5) and Niobium alloy Nb-1 Zr (Ref. 2-6). It is evident that the short term strength of HT-9 is between that for 316 and $20 \mathrm{CW} 316$ to about $500^{\circ} \mathrm{C}$, is equivalent to that for 316 at about $550^{\circ} \mathrm{C}$, and is similar to that for Ti-6Al-4V at about $550^{\circ} \mathrm{C}$. Above $500^{\circ} \mathrm{C}$ HT-9 short term strength decreases rapidly.

The maximum allowable stress intensities, $\mathrm{S}_{\mathrm{mt}}$, of HT-9 and 316 , as defined by the ASME Boiler and Pressure Vessel Code case for elevated temperature design of class 1 nuclear components (N47), are shown for 300,000 hr lifetime as a function of temperature in Table 2-2. (It should be noted that HT-9 is not currently an ASME Code approved material, However, approximate. $S_{m t}$ values were calculated (Ref. 2-2) on the basis of the Case N47 stress criteria.) The allowable design stress intensities take into account both time-Independent and time-dependent creep strength behavior and indicate that for lifetimes on the order of 40 years, which are desirable for commercial power plants, the maximum nominal design temperature for HT-9 components is about $600^{\circ} \mathrm{C}$. 


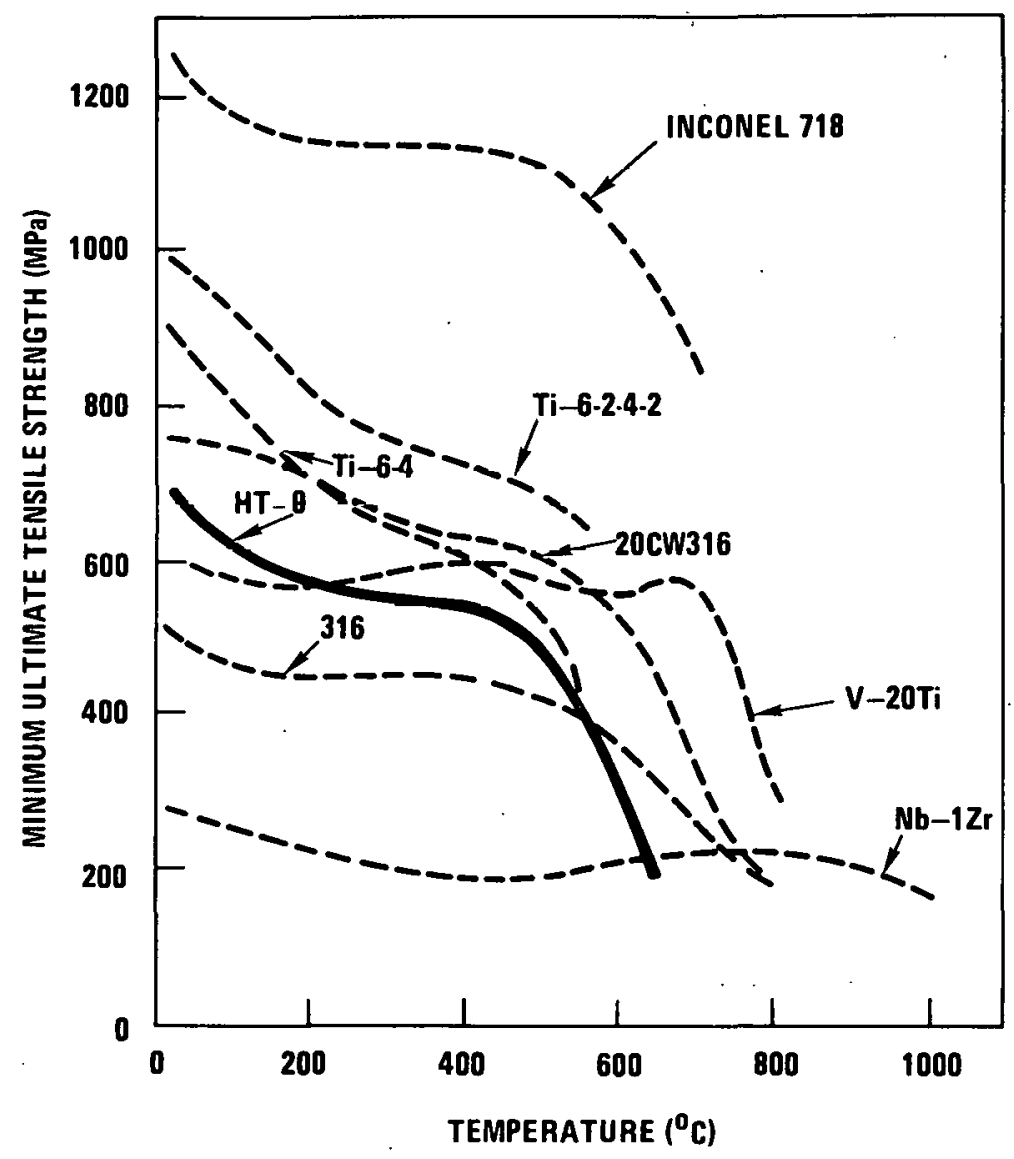

Fig. 2-1. Minimum ultimate strength of HT-9 and other candidate alloys

TABLE 2-2

ALLOWABLE 300,000 HOUR DESIGN STRESSES $\left(\mathrm{S}_{\mathrm{mt}}\right)$ OF HT-9 AND 316 BASED ON THE CRITERIA OF ASME BOILER AND PRESSURE VESSEL CODE CASE N47 (ELEVATED 4 TEMPERATURE SERVICE)

\begin{tabular}{c|c|c|c|c|c|c}
\hline \multirow{2}{*}{ Material } & \multicolumn{5}{|c|}{$\mathrm{S}_{\mathrm{mt}}(\mathrm{MPa})$} \\
\cline { 2 - 7 } & $\mathrm{R} . \mathrm{T}$. & $400^{\circ} \mathrm{C}$ & $500^{\circ} \mathrm{C}$ & $550^{\circ} \mathrm{C}$ & $600^{\circ} \mathrm{C}$ & $650^{\circ} \mathrm{C}$ \\
\hline HT-9 & 227 & 196 & 110 & 62 & 32 & 14 \\
316 & 138 & 110 & 108 & 87 & 50 & 31 \\
\hline
\end{tabular}


Thermal stresses are an important source of cyclic fatigue and creep fatigue damage, particularly in pulsed fusion systems. The comparative resistance to thermal stress can be estimated by a parameter, $M$, defined by

$$
M=\frac{2 \alpha_{y} K(1-v)}{\alpha E} \text {, }
$$

where $\alpha_{\mathrm{y}}$ is the yield strength, $\mathrm{K}$ is the thermal conductivity, $\nu$ is Poisson's ratio, $\alpha$ is the thermal expansion coefficient, and $E$ is Young's Modulus. Thermal stress resistance increases with increasing $M$. The thermal stress resistance of $\mathrm{HT}-9$ at $500^{\circ} \mathrm{C}$ is compared to that of other candidate materials in Table 2-3. The significantly higher thermal conductivity and lower thermal expansion coefficient of ferritic HT-9 relative th alstenitic 316 providoc the former with a significantly greater resistance to thermal stress effects. Thermal stress resistance of HT-9 is slightly lower than that for the Ti alloys and for the precipitation strengthened $\mathrm{Ni}$ alloy 718 .

TABLE 2-3

TIIERMAL STRESS RESISTANCE OF CANDIUATE IUUSLUN ALLOYS AT $500^{\circ} \mathrm{C}$.

\begin{tabular}{l|c}
\hline \multicolumn{1}{c|}{ Alloy } & $\begin{array}{r}\text { Thermal Stress Resistance } \\
\mathrm{M}(\mathrm{W} / \mathrm{m}) \times 10^{-3}\end{array}$ \\
\hline Annealed 316 & 1.3 \\
20CW316 & 4.9 \\
HT-9 & 8.5 \\
Ti-6A1-4V & 10.2 \\
Ti-6Al-2Sn-4Zr-2Mo & 10.4 \\
Incone1 718 & 10.7 \\
V-20Ti & 12.3 \\
Nu-1Zr & 19.8
\end{tabular}




\subsection{RADIATION DAMAGE}

The primary reason for investigating the application of HT-9 is, of course, its apparent resistance to neutron radiation damage. Most of the pertinent information with respect to void swelling,.in-reactor creep, and embrittlement has been developed in the United States FBR program, and has not yet been released for general dissemination. Although discussion of the radiation damage resistance of HT-9 must therefore be qualitative, a number of relevant observations can be made on the basis of EBR II data to greater than $1 \times 10^{23} \mathrm{n} / \mathrm{cm}^{2}(\mathrm{E}>0.1 \mathrm{MeV})$.

Void swelling in HT-9 is at least an order of magnitude less than in 20CW316. Current results indicate that swelling is even lower than the 3.7 percent, $500^{\circ} \mathrm{C}$ peak swelling at $150 \mathrm{dpa}$ previously reported for HT-9 under heavy ion bombardment (Ref. 2-7). The currently published equation for $20 \mathrm{Cw} 316$ (Ref. 2-8) predicts peak swelling of about 35 percent at $580^{\circ} \mathrm{C}$ and $150 \mathrm{dpa}$. In addition, in-reactor creep resistance of HT-9 appears better than that for $20 \mathrm{CW} 316$ to temperatures in excess of $600^{\circ} \mathrm{C}$ (Ref. 2-9).

Although only low helium levels and low helium/dpa ratios relative to fusion neutron conditions have been evaluated, tensile ductility retention of HT-9 appears superior to that for 20CW316 (particularly when tested above the irradiation temperature) and vastly superior to that for the precipitation strengthened nickel alloys up to $600^{\circ} \mathrm{C}$. Furthermore, the microstructure of HT-9 appears stable under irradiation in the temperature range of interest, but the shift in Ductile-Brittle Transttion Temperature after irradiation must be determined.

\subsection{APPLICATION EXPERIENCE}

The class of 9-12 $\mathrm{Cr}$ steels has been used extensively in power generation applications throughout Europe for over 25 years. While most of these applications have been directed towards superheater, reheaters, and evaporators for oil- and coal-fired power plants, much experience and performance history information pertinent to fusion application has been generated. In 
addition to fossil power plant applications, this class of steels has been employed in nuclear power plants. In the Hinkley Point "B" AGR reactor in the United Kingdon, superheaters and reheaters are 9 and $12 \mathrm{Cr}$ steels (Ref. 2-10). In the U.S., the Fort St. Vrain HTGR employs standard 410 and 422 (12 Cr) stainless steel grades in the helium circulators and compressors (Ref. 2-11). Other applications have included gas and steam turbine components, aircraft and missile thin-wall pressure vessels, and petroleum industry pressure vessel linings (Ref. 2-12).

Other proposed nuclear applications for 9-12 Cr steels, presently under consideration, include ducts, cladding, and steam generators for the U.S. LMFBR and GCFR, steam generators for the Japanese FBR, ducts and steam generators for the French Super Phenix, steam generators, helium-helium heat exchangers, helium circulators, and steam piping for the U.S. HTGR, and steam generators for the U.S. LWR.

Two of the largest users for fossil plants in Europe have been Sulzer Brothers (Switzerland) and the United Kingdom Central Electricity Generating Board (CEGB). Table 2-4 indicates the performance and failure histories for

TABLE $2-4$

FOREIGN USAGE AND PERFORMANCE OF 9-12 Cr STEELS IN FOSSIL YOWER PLAN'I'S

\begin{tabular}{|c|c|c|c|c|c|}
\hline LOCATION & USAGE & ALLOY & $\begin{array}{c}\text { TEMPERATUAE } \\
\left({ }^{\circ} \mathrm{C}\right)\end{array}$ & $\begin{array}{l}\text { SERVICE } \\
\text { STATUS } \\
\text { (KHrs) }\end{array}$ & $\begin{array}{l}\text { FAILURE } \\
\text { HISTOAY }\end{array}$ \\
\hline ? & $\begin{array}{l}13 \text { PLANTS } \\
12 \text { PLANTS }\end{array}$ & $\begin{array}{l}9 \mathrm{CrMo}(\mathrm{V}) \\
12 \mathrm{CiMu}\end{array}$ & $\begin{array}{l}450-660 \\
430-850\end{array}$ & $\begin{array}{l}\leqslant 110 \\
\leqslant 45\end{array}$ & $\begin{array}{l}1 \text { FAULTY WELD } \\
1 \text { FAULTY WELD REPAIR } \\
\text { FIRESIOE CORROSION } \\
\text { OVERHEATINO = O5O"C }\end{array}$ \\
\hline $\begin{array}{l}\text { AUSTRIA } \\
\text { BELGIUM } \\
\text { CZECHOSLOVAKIN } \\
\text { GERMANY } \\
\text { SWITZERLAND } \\
\text { TURKEY } \\
\text { YUGOSLAVIA }\end{array}$ & $\begin{array}{l}96 \text { TUNS } \\
>250 \text { TONS }\end{array}$ & $\begin{array}{l}9 \text { Crmo } \\
12 \mathrm{Crmo}(V, W)\end{array}$ & $\leqslant 610$ & $\leqslant 110$ & 1 FAULTY WELD REPAIR \\
\hline
\end{tabular}


these two organizations. In the U.K., CEGB has 25 operating fossil power plants which use 9 and $12 \mathrm{Cr}$ steels. Application temperatures were as high as $850^{\circ} \mathrm{C}$, but successful long-term operation temperatures were limited to the range of $600^{\circ}-650^{\circ} \mathrm{C}$ maximum. At the higher temperatures, overheating contributed to a significant amount of creep damage with correspondingly shorter rupture lives. Of particular interest is the relatively few weld failures. Welding is usually performed following a careful procedure involving pre- and post-weld heat treatments. Only two failures have been reported which related direclly lo welding.

In the lower part of Table 2-4, the countries and total tonnages are reported for Sulzer Brothers fossil power plants. Again, excellent operating performance with only limited failures has been observed.

\subsection{METALLURGICAL PERFORMANCE EVALUATION OF HT-9}

In order to quantify the long-term high-temperature service performance of candidate martensitic stainless steel for fusion application, General Atomic, in conjunction with Sulzer, evaluated the behavior of HT-9 superheater tubing from a welded boiler in the Reutlingen, Germany coal-fired power plant. Tubes were removed from service after 80,000 hours at temperatures near $600^{\circ} \mathrm{C}$. In addition to 720 normal operating starts/shutdowns (50 from room temperature), the tube had also experienced six off normal thermal shocks related to power failures at the plant. 'lihe tubes were subjected to relatively low stresses of approximately 20-50 $\mathrm{MPa}$.

The interrupted service evaluation included stress-rupture, tensile in the temperature range of $23^{\circ}-600^{\circ} \mathrm{C}$, Charpy V-notch impact toughness, and microstructural evaluation. The properties of unexposed tubing were determined simultaneously for comparison.

Figure 2-2 shows the curves obtained in the stress-rupture tests with stress plotted as a function of the Larson-Miller parameters (Ref. 2-14). Overaging of carbides after 80,000 hours of in-service exposure dccreased 


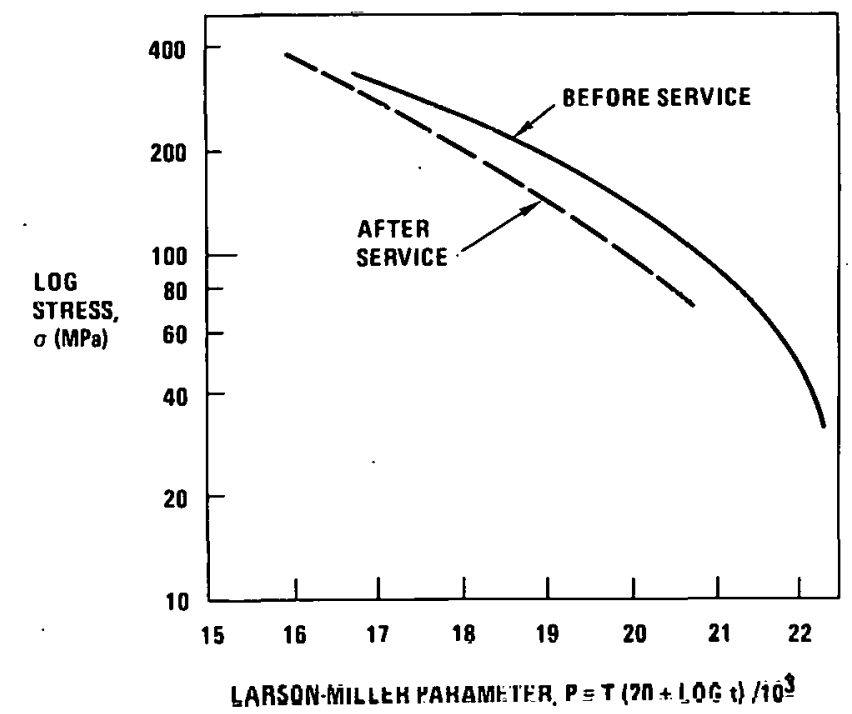

Fig. 2-2. Effect of 80,000 hour, $600^{\circ} \mathrm{C}$ service exposure on $\mathrm{HT}-9$ shiess-rupture properties

stress-rupture lifetimes, particularly at the higher stress levels. As indicated by Fig. 2-2, the residual creep properties were quite good compared to properties before service. It should also be mentioned that total creep strains did not change significantly. Figure 2-3 shows the room- and elevated-temperature tensile properties determined and, again, strength properties were only slightly reduced after long-term service and the tensile

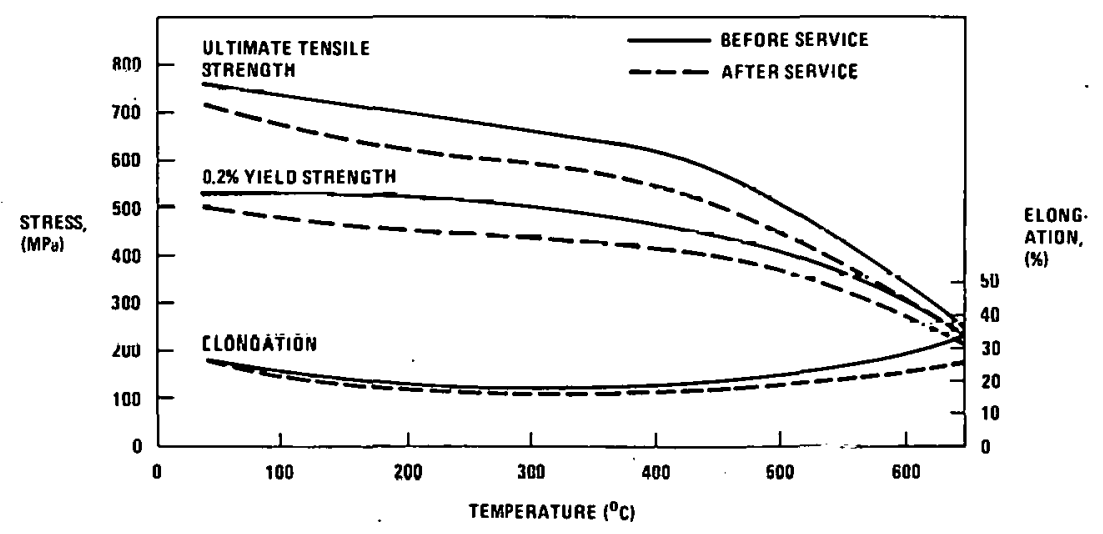

Fig. 2-3. Effect of 80,000 hour, $600^{\circ} \mathrm{C}$ service exposure on HT-9 tensile properties 
ductilities remained quite close to pre-service values over the entire test temperature range. Figure 2-4 shows the impact toughness values obtained at $22^{\circ}$ and $-45^{\circ} \mathrm{C}$, for half-width specimens. Impact toughness decreased; however, substantial toughness remalned even at $-45^{\circ} \mathrm{C}$. This alloy (H'l-9) undergoes a transition in impact fracture behavior from ductile to brittle with decreasing temperature, and following the service exposure, the ductileto-brittle transition temperature (DBTT) shifted to a somewhat higher temperature, although the precise DBTT was not determined in these tests.

Transmission electron microscopy was employed to study the microstructural changes occurring with the service exposure. Overall structural stability appeared to be excellent with the most prominent feature noted as the enhanced precipitation of $\mathrm{M}_{23} \mathrm{C}_{6}$ carbides at martensite interlath boundaries. Some precipitation of a $\mathrm{Fe}_{2}$ Mo laves phase was also noted but was not found to be morphologically detrimental to the mechanical properties. The decrease in impact toughness properties was most likely associated with the carbide precipitation. Thus, the effects of a long-term service exposure did not lead to dramatic reductions in mechanical properties, consistent with the overall good thermal stability of HT-9.

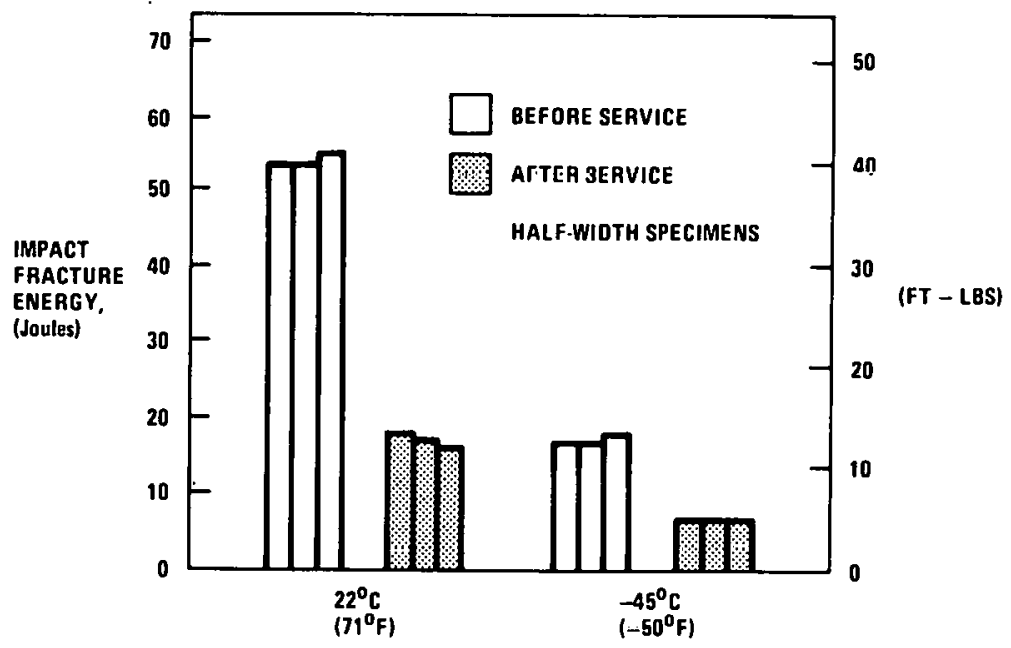

Fig. 2-4. Effect of 80,000 hour, $600^{\circ} \mathrm{C}$ service exposure on HT-9 impact properties 


\subsection{IDENTIFICATION OF KEY ISSUES AND MAJOR DATA REQUIREMENTS}

Based on a detailed evaluation of the known data bases for martensitic steels and fusion design requirements, the key issues which must be resolved for application of 9-12 Cr steels in the Engineering Test Facility (ETF) and future fusion systems were identified as follows:

- fracture resistance - particularly the change of fracture toughness at lower temperature as a result of the ductile-to-brittle transition behavior characteristics of these steels;

- the effect of the fusion reactor environment on structural properties - including the effects of displacement damage and transmutation products from interaction with fusion $14 \mathrm{MeV}$ neutrons and the compatibility with candidate coolants;

- weldability/fabricability - specifically pre- and post-weld heat treatment requirements, cracking susceptibility, repair procedures in configurations pertinent to fusion applications, and the sensitivity of weld procedures to microstructure and properties.

In connection with the above evaluations and assessment of the data base which exists for the two leading martensitic steel candidates for fusion application, HT-9 and developmental modified $9 \mathrm{Cr}-1$ Mo alloy (being developed) by ORNL for the FBR program under DOE funding) was completed. Table 2-5, which shows the properties of interest and an assessment of our current level of knowledge, indicates major data voids in the area of fatigue and fracture related properties, weld properties, irradiation performance and coolant compatibility effects for both alloys.

As a result of this study, a comprehensive testing program, with the objective of establishing the application feasibility and performance potential of 9-12 $\mathrm{Cr}$ magnetic steels in ETF and other fusion systems, was recommended to DOE-OFE and a major national program was initiated in FY- 80 . 
TABLE 2-5

CURRENT DATA BASE FOR HT-9 AND

MODIFIED $9 \mathrm{Cr}-1$ Mo

\begin{tabular}{|c|c|c|c|c|}
\hline \multirow{2}{*}{ PROPERTY } & \multicolumn{2}{|c|}{ HT-9 } & \multicolumn{2}{|c|}{ MODIFIED $9 \mathrm{Cr}-1 \mathrm{Mo}$} \\
\hline & UNIRRADIATED & IRRADIATED & UNIRRADIATED & IRAADIATED \\
\hline TENSILE & - & 0 & - & 0 \\
\hline STRESS-RUPTURE & - & 0 & $\bullet$ & 0 \\
\hline CREEP & $\bullet$ & $\theta$ & $\bullet$ & 0 \\
\hline VOID SWELLING & & $\bullet$ & & o \\
\hline CREEP.FATIGUE & 0 & 0 & 0 & 0 \\
\hline FATIGUE CRACK GROWTH & 0 & 0 & $\Omega$ & $n$ \\
\hline FRACTURE TOUGHNESS & o & 0 & $\Omega$ & $n$ \\
\hline IMPACT TOUGHNESS & $\bullet$ & 0 & $\bullet$ & 0 \\
\hline WELD PROPERTIES & $\bullet$ & O & $\bullet$ & 0 \\
\hline COOLANT COMPATIBILITY & $\bullet$ & o & 0 & 0 \\
\hline PHYSICAL PROPERTIES & $\bullet$ & 0 & 0 & 0 \\
\hline MAGNETIC PROPERTIES & 0 & 0 & $\bullet$ & 0 \\
\hline
\end{tabular}

\section{REFERENCES}

2-1 KING, R. T., GOODWIN, G. M., HEESTAND, R. L., DEVAN, J. H. and MCCURDY, H. C., "Alternate Structural Materials for Liquid Metal Fast Breeder Reactors," Symposium on Structural Material for Service at Elevated Temperatures in Nuclear Power Generation, A. 0. Schaefer, Ed., Houston, Texas, November 1975, ASME, New York, p. 375.

2-2 CHAFEY, J. E. and WATTIER, J. B., "Estimation of Allowable Design Stress Values for $12 \mathrm{Cr}-1$ Mo-0.3 V Steel," General Atomic Report GA-A14610, February 1978.

2-3 SPANNER, J. C., Ed., NUCLEAR SYSTEMS MATERIALS HANDBOOK, Vol. 1, DESIGN DATA, TID 26666, Handford Engineering Development Laboratory (1976).

2-4 METALLIC MATERIALS AND ELEMENTS FOR AEROSPACE VEHICLE STRUCTURE, HIL-HBKC-5B, Sections 5.3.3 and 5.4.3, USAF (1975).

2-5 GOLD, R. E., HARROD, D. E., AMMON, R. L., BUCKMAN, R. W., JR. and SVEDBERG, R. S., "Technical Assessment of Vanadium Base Alloys for Fusion Reactor Applications," Final Report No. C00-4540-1, Westinghouse Electric Corp., Apri1 1978, p. 112. 
2-6 DAVIS, J. W. and KULCINSKI, G. L., "Assessment of Titanium for Use in the 1st Wa11/Blanket Structure of Fusion Power Reactors," EPRI ER 386, McDonnell Douglas Astronautics Company, April 1977, p. 10.

2-7 SMIDT, F. A., MALMBERG, P. R., SPRAGUE, J. A. and WESTMORELAND, J. G., "Swelling Behavior of Commerclal Ferritlc Alloys, EM-12 and HT-9, as Assessed by Heavy Ion Bombardment," IRRADIATION EFFECTS ON THE MICROSTRUCTURE AND PROPERTIES OF METALS, ASTM STP \#611, American Society for Testing and Materials (1976) p. 227.

2-8 SPANNER, J. C., Ed., NUCLEAR SYSTEMS MATERIALS HANDBOOK, Vol. 1, DESIGN DATA, TID 26666, Handford Engineering Development Laboratory (1976), Sect1on 5 .

2-9 CHIN, B. A., GILBERT, E: R., PAXTON, M. M. and STRAALSUND, J. L., "A Comparison of the In-Reactor Creep Behavior of Selected Commerclal Alloys at a Temperature of $593^{\circ} \mathrm{C}, "$ presented at the 9 th ASTM International Symposium on Effects of Radiation on Structural Materials, Richland, Washington, July 1978.

2-10 WYATT, L. M., "The Performance of Cr-Mo Steels in the Boilers of CEGB Power Stations," FERRITIC STEELS FOR FAST REACTOR STEAM GENERATORS, edited by S. F. Pugh and E. A. Little (1978), Proceedings of an International Conference held by the British Nuclear Energy 3üiely at the Institution of Civil Engineers, London, May 30 through June 2, 1977.

2-11 SMITH, A., General Atomic Company, private communication.

2-12 BRIGGS, J. Z. and PARKER, T. D., THE SUPER 12\% CR STEELS, Climax Molybdenum Company, Ann Arbor, Michigan (1965).

2-13 FRICKER, H., "Sulzer Experience with High Chromium Ferrit1c Steels," Report TA 2730, Sulzer Brothers, Switzerland, February 1977.

2-14 WALSER, B., "The Metallurgical and Mechanical Properties of X20CrMoWV121 After Service Exposure in a Fossil Fired Botler," Report 222/1511, Sulzer Brothers, Switzerland, January 1977. 


\section{LIFETIME ANALYSIS}

The primary incentive for using HT-9 in a fusion environment is its resistance to irradiation damage which means increased lifetime for components.

Lifetime of the first wall/blanket has a significant impact on the economics of a fusion reactor for numerous reasons. The first is the downtime required to periodically replace components whose lifetimes are used

up, in the sense that reliable operation is no longer obtained. This is particularly important since the components need to be removed and replaced using remote maintenance equipment which is notoriously slow and expensive. A second factor contributing to cost is the cost for multiple components. This includes not only the cost for material and fabrication, but also the added expense of managing an inventory of replacement components. A third factor is related to the waste management of the activated structural materials. Components with extended lifetimes will be activated to a greater degree than shorter-lived components, but the volume of activated material that needs to be handled and disposed of will be significantly less. In summary, increased component lifetime reduces cost and makes fusion power more attractive in many ways.

\subsection{MODEL EMPLOYED}

A computer systems code was developed for a typical helium cooled canister type tritium breeding blanket module in order to provide a basis. for comparison of different materials. In this analysis, the 11fettme of a module made from HT-9 is compared to that using $20 \%$ CW 316 stainless steel. It is important not to simply take an existing module design based on one material and substitute another and calculate a lifetime. Each 
design must be optimized for a given choice of material; this is done here by letting the wall thickness be an independent variable.

For comparison purposes, numerous blanket design parameters are held constant. The module diameter is assumed to be $0.5 \mathrm{~m}$ and the helium pressure is 40 atmospheres (600 psi). The helium inlet temperature is fixed at $250^{\circ} \mathrm{C}$ and the outlet temperature at $525^{\circ} \mathrm{C}$. The front wall of the module is exposed to the plasma heat flux without using a divertor or a separately cooled fisst wall. The neutron wall loading is $1 \mathrm{MW} / \mathrm{m}^{2}$ which is $80 \%$ of the total wall loading. A repetitive duty cycle of $300 \mathrm{~s}$ burn time followed by a $30 \mathrm{~s}$ dwe1.1. is used to oalculate first wall operating temperature, the temperature difference across the wall, and the cyclic variation of temperature with time. (The thermal analysis was obtained from the General Atumle Demonstration Power Reactor study (Ref. 3-1) and was extended for the different choices of materia1.) The analysis is for the very front of the dished (ellipsoidal) head of the module where the temperature is a maximum and the pressure stress is uniform tension in all directions, given by the famillar relation $\mathrm{pR} / \mathrm{t}$. Superposed on this steady stress is a bending stress produced by the temperature difference across the wall thickness. Linear elastic stress analysis has been assumed throughout, aojuming sliakedown during the first few cycles after startup. The bending stress is cyclic and is the source of fatigue and crack growth failures.

Temperature dependent material properties are used In all caleulatiuns since considerable temperature variations are encountcrcd. The insldntaneous coefficient of thermal expansion is used in the calculation, rather than the mean value from room temperature since the cycling is about an elevater average temperature.

Beforc any lifetime calculations commence, the acceptability of the modulc design is checked against Section III of the ASME Boiler and Pressure Vessel Code, namely, that the primary (pressure) stress is less that $\mathrm{s}_{\mathrm{m}}$, where $\mathrm{S}_{\mathrm{m}}$ is the maximum of either 0.9 of the yield strength or $1 / 3$ of the ultimate 
strength, both at the wall-averaged temperature. In addition, the maximum stress due to pressure and temperature is ascertained to be less than $3 \mathrm{~S}_{\mathrm{m}}$. If either of these two criteria are not met, no further calculations are performed.

Material property data for both $20 \% \mathrm{CW} 316$ and HT-9 were the most recent - data available as of June 1979. Whenever possible, material data for 316 was obtained from the Nuclear Systems Materlals Handbook (Ref. 3-2). In addition, References 3-3 and 3-4 were used. For HT-9, material data was obtained from unpublished data from the U.S. LMFBK fuel cladding and duct program.

Four mechanisms of failure were considered in determining the lifetime of the blanket module: combined creep rupture-fatigue, crack growth of an" assumed initial flow, volumetric swelling, and strain (distortion) limits. Each calculation is discussed separately.

Linear interaction of fatigue and creep rupture is assumed. Life use fractions are calculated, as recommended by Code Case N47 of the ASME Code, so that the sum of the creep rupture use fraction and the low and high cycle fatigue use fractions equals unity. Creep rupture life is based on the primary pressure stress and the maximum wall-averaged temperature for the entire duty cycle time. Both low cycle fatigue, due to startup/shutdown cycling, and high cycle fatigue, due to thermal cycling of the first wall, are consldered. The1r use fractions are added together just as the fatigue fraction is added to the creep rupture fraction. It is implicitly assumed that 40,000 duty cycles occur each startup/shutdown cycle.

For the crack growth calculation; a 2:1 elliptical surface flaw is assumed to be on the inside surface of the blanket module wall, in the worst orientation. 'l'hermal cycling of the module wall produces time varying tensile stresses which together with the primary stress causes the flaw to grow until the flaw propagates through the entire thickness of the wall, at which time failure occurs. The mode of failure is leakage of helium coolant into the plasma chamber, a phenomenon which prevents the plasma from reacting. 
The initial depth of the flaw is assumed to be $0.75 \mathrm{~mm}$. Elastic stress intensity magnification factors as a function of crack depth for the case of bending were obtained from Ref. 3-5. The number of cycles for the flaw to travel one tenth the distance to failure was calculated ten successive times and the total number of cycles to failure was determined. Lifetime is then simply the total number of cycles times the cycle time, in this case, $330 \mathrm{~s}$.

Life based on volumetric swelling is based on stress-free swelling data which assumes an incubation dose during which no sweiling takes place, followed by an exponential increase with fluence. A fluence of $1 \mathrm{MW}-\mathrm{yr} / \mathrm{m}^{2}$ is taken to represent $2.2 \times 10^{22}$ neutrons $/ \mathrm{cm}^{2}$. This was determined by taking into account that $14 \mathrm{Mev}$ fusion neutrons produce approximately $60 \%$ more dpa's than that obtained from EBR II fluences ( $\geq 0.1 \mathrm{Mev}$ ). A $3 \%$ limit on volumetric swelling was somewhat arbitrarily chosen as the end-oflife criterion. This represents a linear strain of $1 \%$.

Life based on strain limits was determined when the combined irradiation and thermal creep reached 3\% linear strain. The material data used for this calculation are referred to as in-reactor creep. It is a function of both tempcraturc and stress.

\subsection{RESULTS AND DISCUSSION}

Figure 3.1 is a comparison of lifetimes for the two materials as a function of maximum wall temperature, which is controlled by the coolant outlet temperature. For both materials, it was found that lifetime is not limited by the mechanism of combined creep-fatigue and thus does not appear in the figure. This is understandable since fatigue is a less stringent requirement than crack growth propagation and strain limits control before creep rupture occurs. Lifetime based on swelling is straightforward and is primarily a function of wall-averaged temperature. HT-9's superior resistance to swelling compared to 316 is clearly evident. At a maximum wall temperature of $550^{\circ} \mathrm{C}$, the ratio of swelling lifetimes is 5 to 1 . 


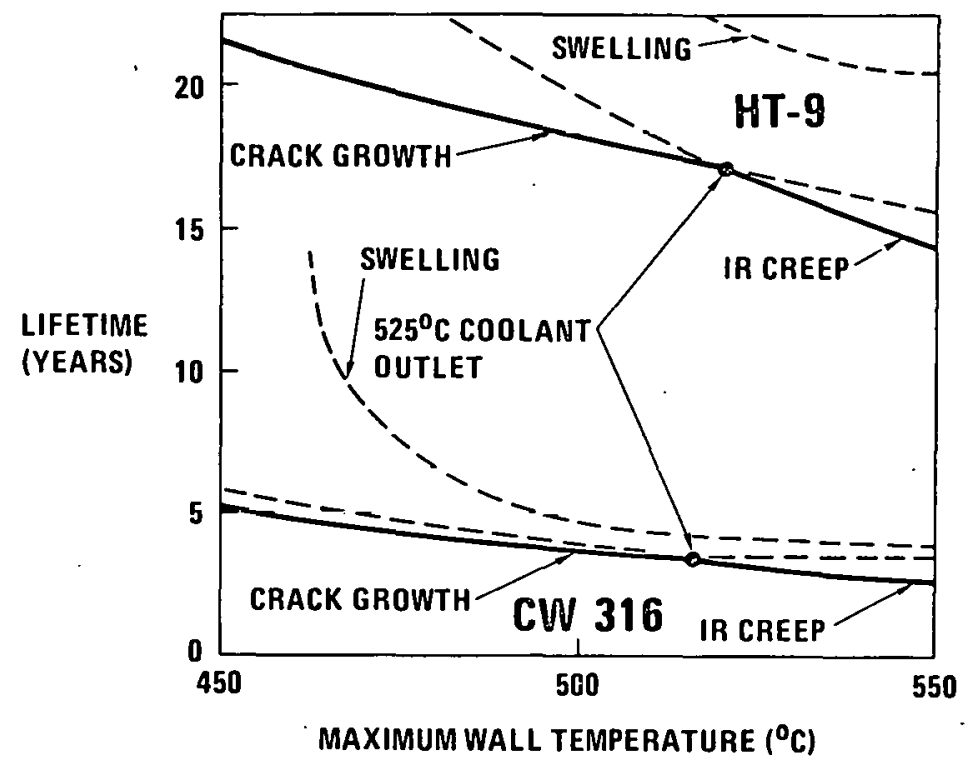

Fig. 3-1. Systems lifetime comparison of HT-9 with $20 \% \mathrm{CW} 316$ for a neutron wall loading of $1 \mathrm{MW} / \mathrm{m}^{2}$

Lifetime based on crack growth and strain limits is a function of wall thickness and hence is controllable. For each material and for a helium outlet temperature of $525^{\circ} \mathrm{C}$, the wall thickness was varied until the lifetime based on crack growth equaled that based on strain limits. For example, increasing the wall thickness decreases the crack growth life since the temperature difference across the wall thickness is increaged which means increased bending stress. At the same time, increasing the wall thickness increases the strain limit life since the primary stress is reduced and creep strain is inversely proportional to primary stress. For an outlet coolant temperature of $525^{\circ} \mathrm{C}$, life based on crack growth equals that based on strain limits when the wall thickness is $1.2 \mathrm{~cm}$ for HT-9 and $0.83 \mathrm{~cm}$ for 316 . This means that the primary stress for the HT-9 module ( $86.2 \mathrm{MPa}$ or $12,500 \mathrm{psi}$ ) is liess than that for the 316 module (123 $\mathrm{MPa}$ or 17,800 psi). Wall-averaged temperature for both materials is approximately the same, $465^{\circ} \mathrm{C}$, with HT-9 having a slightly greater temperature difference across the wall; but the thermal bending stress is less, $17 \mathrm{MPa}$ 
$(24,800 \mathrm{psi})$ as compared to $241 \mathrm{MPa}(34,900 \mathrm{psi})$ for 316 . The load ratio (minimum stress divided by maximum stress) is the same for both materials, -0.33 .

It is clear from F1g. 3.1 that the lifetime of the HT-9 module wall, $17.1 \mathrm{MW}-\mathrm{yr} / \mathrm{m}^{2}$, is approximately five times greater than that of $20 \% \mathrm{CW} 316$, $3.5 \mathrm{MW}-\mathrm{yr} / \mathrm{m}^{2}$. This is attributable to the fact that the HT-9 wall thickness is greater than that of 316 , which decreases the primary stress to achieve greater life for the same strain limit, yet not at the expense of decreased crack growth life because the thermal stresses are lower than those of. 316 . While for this study the specific result for the ratio of 1ifetimes of HT-9 and 316 depends upon specific design criteria, e.g. the allowed linear strain, the factor of five improvement observed in HT-9 does indicate a significant advantage of using martensitic stainless steels. To more accurately determine the lifetime ratio as well as the actual number of $M W-y r / m^{2}$ of life requires additional effort in both depth and breadth. In particular, the lifetime calculation is very dependent on the end-of-life criteria chosen for such things as swelling and maximum strain limits. These criteria can be developed with more confidence only by involving more people in the design of the first wall/blanket and developing designs in greater detail. Also, as pointed out earlier, separate blanket designs need to be developed for earh material in order to optimize the advantages each material has to offer.

\subsection{IMPLICATIONS FOR POTENTIAL APPLICATION TO ETF}

Introduction of martensitic stainless steels to the ETF program would not dramatically impact the design of the first wall/blanket since the proposed doses are presently believed to be within the capability of $20 \% \mathrm{CW} 316$ stalnless steel. However, introduction of martensitic stainless steels in ETF in conjunction with 316 will allow a comparison of performance to substantiate claims of extended lifetime. In addition, material behavior in a fusion environment can be quantified. Nothing can be a better test for resistance to fusion spectrum irradiation than actual large-dose exposure only the ETF can provide. 
REFERENCES

3-1 "Doublet Demonstration Fusion Power Reactor Study," Fusion Engineering Staff, General Atomic Report GA-A14742.

3-2 Nuclear Systems Materials Handbook, Vo1. I, Design Data, TID-26666, Hanford Engineering Development Laboratory (1976).

3-3 S00, P. and McANDREW, J., "Type 303 and Type 316 Stainless Steel Data for High Temperature Design," Westinghouse Report WARD 3045T2C-3.

3-4 JAMES, L. A., "Fatigue-Crack Growth in 20\% Cold-Worked Type 316 Stainless Steel at Elevated Temperatures," Nuclear Technology 16, 316 (October 1972).

3-5 SHAH, R. C. and KOBAYASHI, A. S., "On the Surface Flaw Problem," The Surface Crack: Physical Problems and Computational Solutions, ASME Publication, 79-124 (1972). 


\section{MEASUREMENT OF MAGNETIC PROPERTIES}

\subsection{INTRODUCTION}

There is very little information in the literature on the magnetic properties of ferromagnetic stainless steels, particularly as a function of temperature and previous cold work and tempering. Some preliminary measurements on $12 \mathrm{Cr} 1$ Mo (HT-9) were reported (Ref. 4-1) at the First Topical Meeting on Fusion Reactor Materials. This section reports some additional measurements on both $12 \mathrm{Cr} 1$ Mo and $9 \mathrm{Cr} 2$ Mo as a function of temperature and bias field. Walter Praeg has done some interesting and important measurements on the latter alloy (Ref. 4-3).

Since these steels are hard magnetic materials, there is considerable area within the hysteresis loop, whose shape changés as the maximum inducing magnetic field is varied. Also the magnetic properties depend on the past history of the material; they are influenced by heat treatment and work hardening.

It is fortunate for tokamak reactor applications that the material near the plasma i.s completely saturated by the applied steady-state toroidal field and the key parameter in quantifying the magnetic effects on reactor design and operation is the value of the saturation induction.

\subsection{PREVIOUS RESULTS}

In Ref. 4-1, two types of experiments were reported. In the first, a hollow cylinder with a length several times the outer radius was placed in a steady magnetic field parallel to the symmetry axis. There were two coils wound around the cylinder. One was located about halfway between the equatorial plane and the top end of the cylinder and the other was about halfway between the equatorial plane and the bottom end of the cylinder. The ratio 
of the measured mutual inductance to the calculated value for the same geometry in vacuum was determined at $200^{\circ} \mathrm{C}$. As shown in Table 5 of Ref. 4-1, the ratio fell from 23 at zero field to about unity for magnetic fields stronger than 2000 oersted. The accuracy of the experiment was only about $10 \%$. In this geometry, in which the fields coupling the coils are nearly parallel to the axis, a value of unity is expected for large bias fields.

The second experiment employed a bias field which was parallel to the symmetry axis of a toroidal transformer with two complete sets of circular windings. The field created by currents in the primary windings is orthogonal to the steady-state bias field, which can be quite large. As Table 4 of Ref. 4-1 indicates, the ac permeability drops from a value of 76 at zero bias to a value of about 1.3 for external bias fields greater than 20,000 oersted. That the permeability does not reach unity is to be expected for this geometry where it should approximate $\left(B_{0}+B_{s a t}\right) / B_{0}$. Here $B_{0}$ is the inducing field in the steel in the absence of a primary current and $B_{\text {sat }}$ is the intrinsic induction associated with complete alignment of the magnetic domains in the material (Ref. 4-4).

The calculation of magnetic effects under reactor conditions where the electrical currents and geometry have been specified is very tedinus hut the only magnetic parameter required is the value of $\mathrm{B}_{s_{s}}$. The IRON code described in Ref. 4-2 and Section 5 performs these calculations expeditiously.

\subsection{CURRENT EXPERIMENTS}

One purpose of the current experiments has been to compare two representative martensitic stainless steels under simulated tokamak reactor conditions. The most important parameter to measure is the saturation induction, $B_{S}$, as a function of temperature. A second purpose has been to examine the response of a material placed in a large $\left(>B_{s}\right)$ steady state field $B_{0}$ when subjected to a smaller, sinusoidal field, thus simulating the toroidal and poloidal fields, respectively. It is found that the area within the hysteresis loops vanishes and the $\mathrm{B}$ vs $\mathrm{H}$ relationship becomes linear, indicating 
that the material is now paramagnetic. The permeability approaches $\left(B_{0}+B_{S}\right) / B_{0}$ as $B_{0} \gg B_{s}$. If the bias field is parallel to the sinusoidal field, the permeability is unity for $B_{0}>B_{S}$.

Three toroidal transformers were built; two from $9 \mathrm{Cr} 2$ Mo and the other from $12 \mathrm{Cr} 1 \mathrm{Mo}$ (HT-9). Their characteristics are given in Table 4-1.

Glass covered, \#32, copper wire was used for the windings: One layer of glass tape separated the primary from the secondary. A chromel alumel thermocouple was fastened with glass tape to the secondary to measure the temperature of the sample. The transformer was wound with several layers of wet asbestos paper tape until the hole in the torus was almost filled. Successive layers of Min-K insulation, aluminum foil and glass tape were added until the shape approximated an oblate spheroid $4 \mathrm{~cm}$ in height and $8 \mathrm{~cm}$ in diameter.

The primary served two functions. It provided a magnetizing field and also served as a heater. About ten watts would take the sample to $500^{\circ} \mathrm{C}$. The voltage across a shunt resistance in series with the primary was connected to the $x$-axis of an oscillograph and the voltage developed by the

TABLE $4-1$

CHARACTERISTICS OF TOROIDAL TRANSFORMERS USED FOR MATERIAL EVALUATION

\begin{tabular}{l|l|l|l|l|l}
\hline \multicolumn{1}{c|}{ Material } & $\mathrm{N}_{\mathrm{P}}$ & $\mathrm{N}_{\mathrm{s}}$ & $\begin{array}{l}\mathrm{A}_{\text {core }} \mathrm{cm}^{2} \\
\mathrm{~cm}^{2}\end{array}$ & $\begin{array}{l}\Delta \mathrm{A} \\
\mathrm{cm}\end{array}$ \\
\hline 12 Cr 1 Mo parallel & 151 & 129 & 0.273 & 0.048 & 1.39 \\
$9 \mathrm{Cr} 2$ Mo parallel & 186 & 156 & 0.341 & 0.065 & 1.67 \\
\hline
\end{tabular}

$A_{\text {core }}$ is cross sectional area of magnetic core $\triangle A$, is area between core and center of primary wires

$R$ is major radius of torus

$\mathrm{N}_{P}$ is the number of turns in the primary winding

$\mathrm{N}_{\mathrm{S}}$ is the number of turns in the secondary winding 
secondary was fed through an integrating circuit to the y-axis. The resulting hysteresis loop was photographed and all measurements reported here were made at $60 \mathrm{~Hz}$. The sample size was small enough that eddy current effects were minimal.

The general procedure was to keep the primary current steady until the desired temperature was reached. After the hysteresis loop was photographed, measurements were also made at smaller and larger primary currents as rapidly as possible becalise the sore would cool off or lieal up. As the thermal time constant was several minutes, the changes in core temperature from the steady state value are believed to be small.

'l'he three transformers were placed in a cylinder of tightly packed Min-K insulation about $9.5 \mathrm{~cm}$ in diameter and $30 \mathrm{~cm}$ long. The central coil was of $12 \dot{C r} 1$ Mo and its axis was horizontal. The other coils were placed as close as possible with their axis vertical. The package slid tightly into a non-magnetic stainless steel tube $150 \mathrm{~cm}$ long and the 18 leads run through a hole in the rubber stopper which was stuffed with silicone rubber. The stainless steel tube could be evacuated and back filled with nitrogen or dry air. This assembly was in turn inserted into a glaoo dewar which pene= trated the high fleld superconducting snlennid. It has a 40 in bore and a length of $42 \mathrm{~cm}$. The central transformer was located at the center of the superconducting solenoid.

\subsection{RESULTS}

The hysteresis loops for no bias field were obtalned with the sample out of the superconducting magnet. Figure 4-1 shows the hysteresis loops for two different maximum primary currents for $12 \mathrm{Cr} 1 \mathrm{Mo}$ at $500^{\circ} \mathrm{C}$. Figure 4-2 1ndicates how the hysteresis loop changes as a function of temperature. The areas herome smaller and the saturation inductance decreases with increasing temperature. The maximum magnetizing field used was 300 oersted. To the reactor designer, the only information of interest is the value of the magnetic induction at which the material is well saturated. 


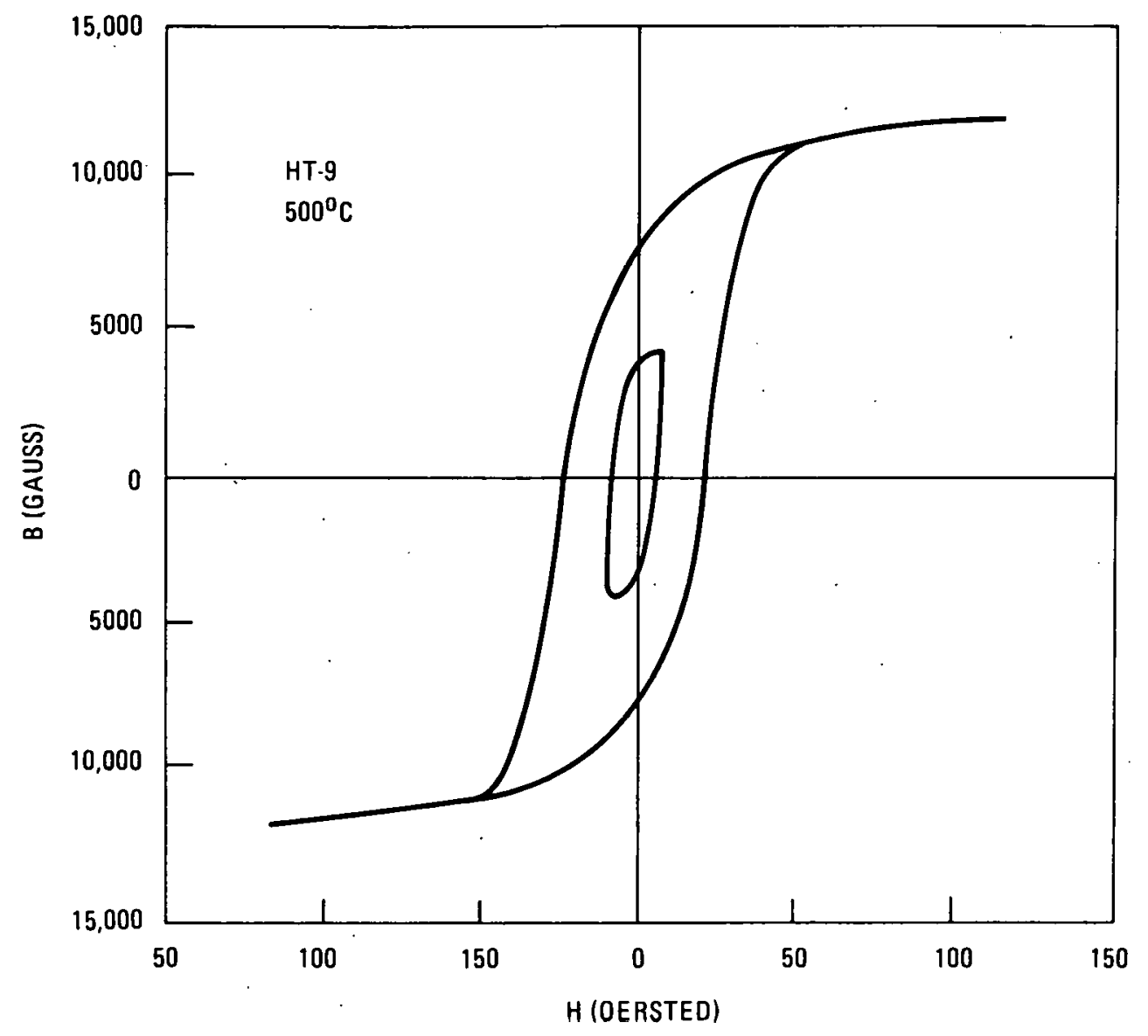

Fig. 4-1. Comparicon of hyeteresis $100 \mathrm{ps}$ of HT-9 at $500^{\circ} \mathrm{C}$ for two different maximum primary currents

Because of the finite time constant in the integrating circuit and the 300 oersted limit on the magnetizing field, the absolute value for the saturation induction may be in error by $10 \%$, but the relative values for different temperatures and materials are accurate to a few percent.

Figure 4-3 compares $12 \mathrm{Cr} 1$ Mo with $9 \mathrm{Cr} 2$ Mo at $500^{\circ} \mathrm{C}$. The saturation induction is slightly larger for $9 \mathrm{Cr} 2$ Mo. Table 4-2 lists some values of the induction near saturation at two temperatures for the three samples. 


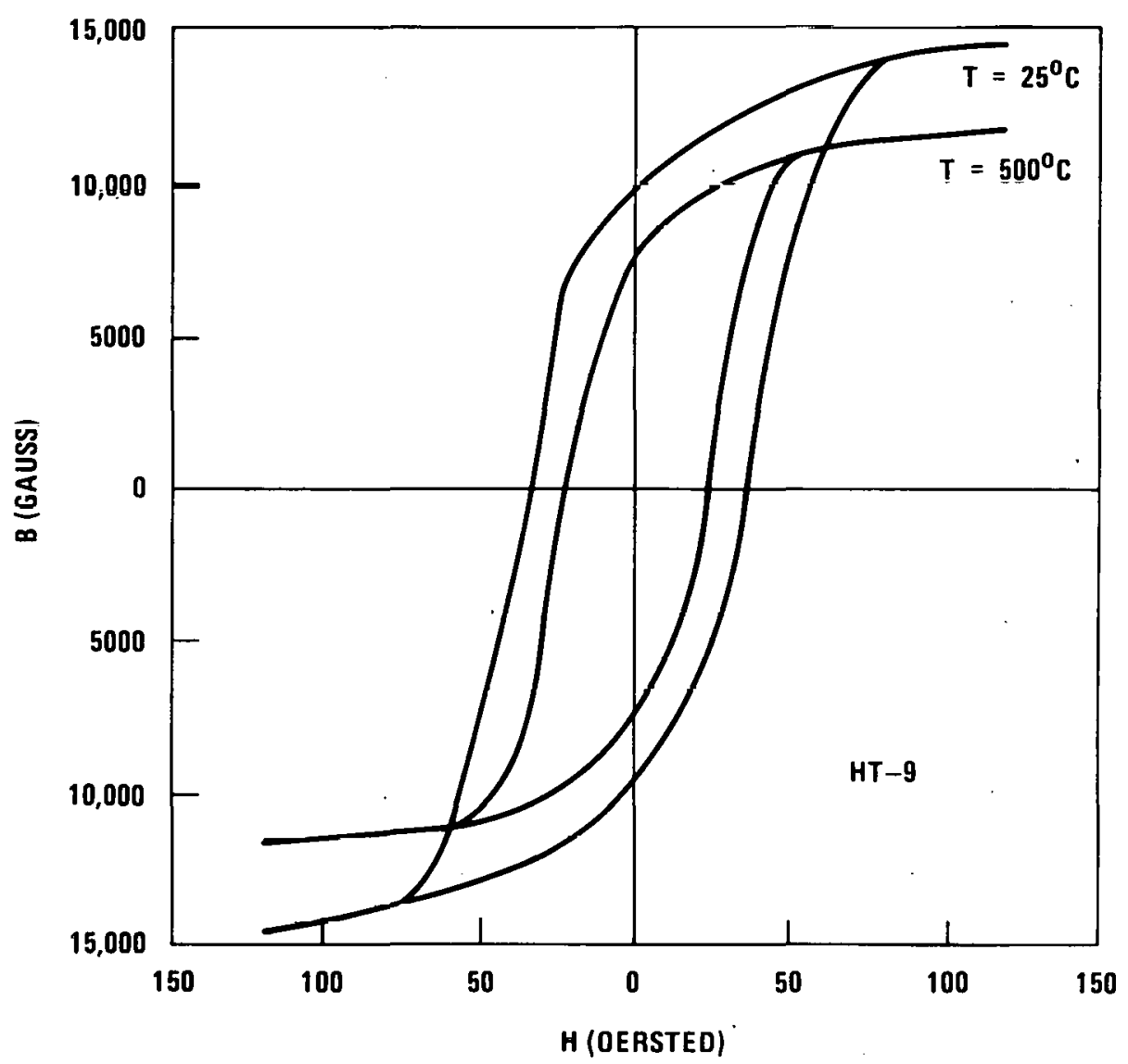

Fig. 4-2. Comparison of the hysteresis loops for $12 \mathrm{Cr} 1$ Mo at room temperature and a typical operating temperature in reactor applications

TABLE $4-2$

SATIRATTON TNDUICTION AS A FUNCTION OF TEMPERATURE

\begin{tabular}{l|c|c|c|c}
\hline \multirow{2}{*}{ Temperature } & \multicolumn{2}{c}{$25^{\circ} \mathrm{C}$} & \multicolumn{2}{c}{$500^{\circ} \mathrm{C}$} \\
\hline & $\mathrm{H}$ & $\mathrm{B}$ & $\mathrm{H}$ & $\mathrm{B}$ \\
\cline { 2 - 6 } & Oersted & Gauss & Oerśtèd & Gauss \\
\cline { 2 - 6 } $12 \mathrm{Cr} 1$ Mo, parallel & 124 & 14,100 & 122 & 11,100 \\
$12 \mathrm{Cr} 1$ Mo, perpendicular & 127 & 14,200 & 125 & 11,900 \\
$9 \mathrm{Cr} 2$ Mo, parallel & 133 & 16,200 & 127 & 13,300 \\
\hline
\end{tabular}




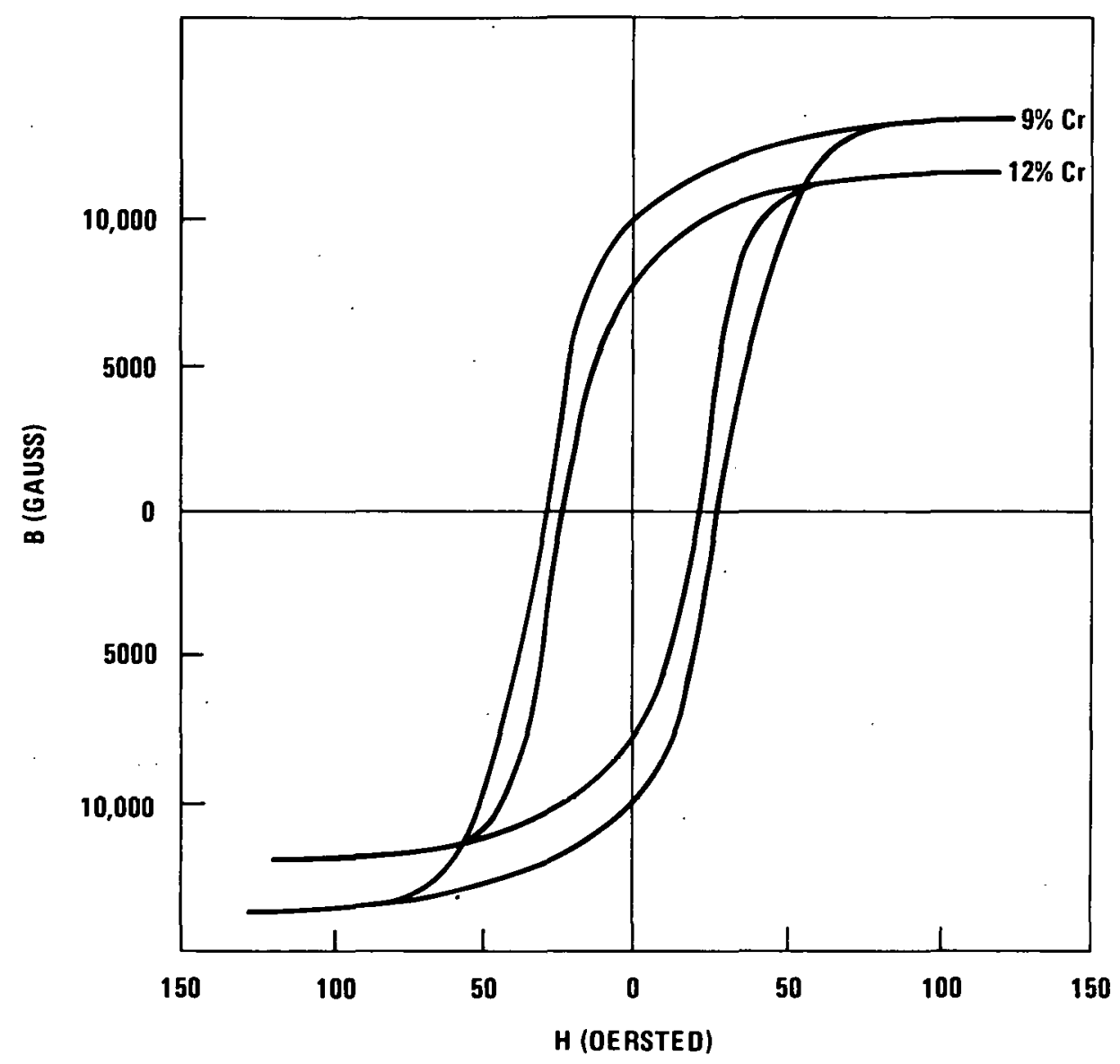

Fig. 4-3. Comparison of $9 \mathrm{Cr}$ and $12 \mathrm{Cr}$ martensitic steel hysteresis loops at $500^{\circ} \mathrm{C}$

Because of scheduling difficulties and the high cost of liquid helium, only one set of measurements with a large bias field was possible. The striking result is the manner in which the hysteresis loop diminishes in area and becomes a straight line whose slope decreases as the bias field increases. Figures 4-4 and 4-5 illustrate this for the $12 \cdot \mathrm{Cr} 1$ Mo sample with its symmetry axis parallel to the bias field.

When the bias field is increased above 40,000 oersted, appreciable forces are exerted on the primary wires when they carry a current of 10 amp or more. There is evidence that some motion resulted. Before two of the 


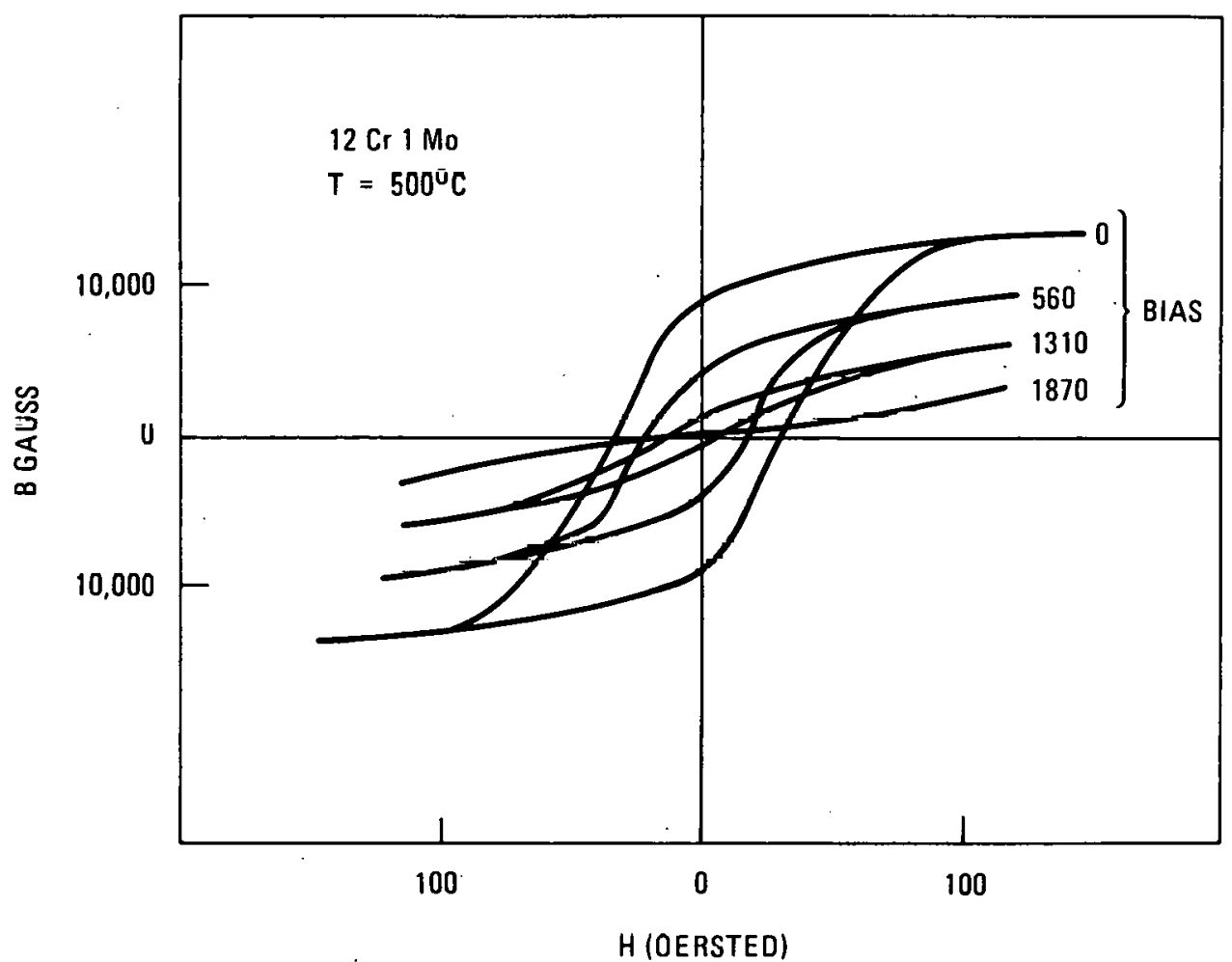

Fig. 4-4. Variation in hysteresis loops with bias field

primaries developed an open circuit at 60,000 oersted, wiggles appeared about the straight line of the $B$ vs $H$ relationship. A possible interpretation is that motion of the sample or primary leads moved the secondary leads across the large bias field inducing a spurious voltage. The behavior of the $9 \mathrm{CK} 2$ Mo sample was quite similar to that shown in Fig. 4-5 and the $12 \mathrm{Cr} 1$ Mo sample except that the value of $\mathrm{B}_{s}$ inferred from the slope of the $B$ vs $\mathrm{H}$ line was about 14,000 gauss at $500^{\circ} \mathrm{C}$.

Calculation of $B_{G}$ from the $B$ vs $H$ curve when a bias field is present is not straightforward. The slope of the line is larger than the true permeability, $\mu$, of the core material because the bias field in the sample is less than the value of the bias field produced by the superconducting magnet. For an infinite cylinder in a uniform field, the magnetizing field inside the sample is $2 /(1+\mu)$ times the value of the uniform field. For example, 


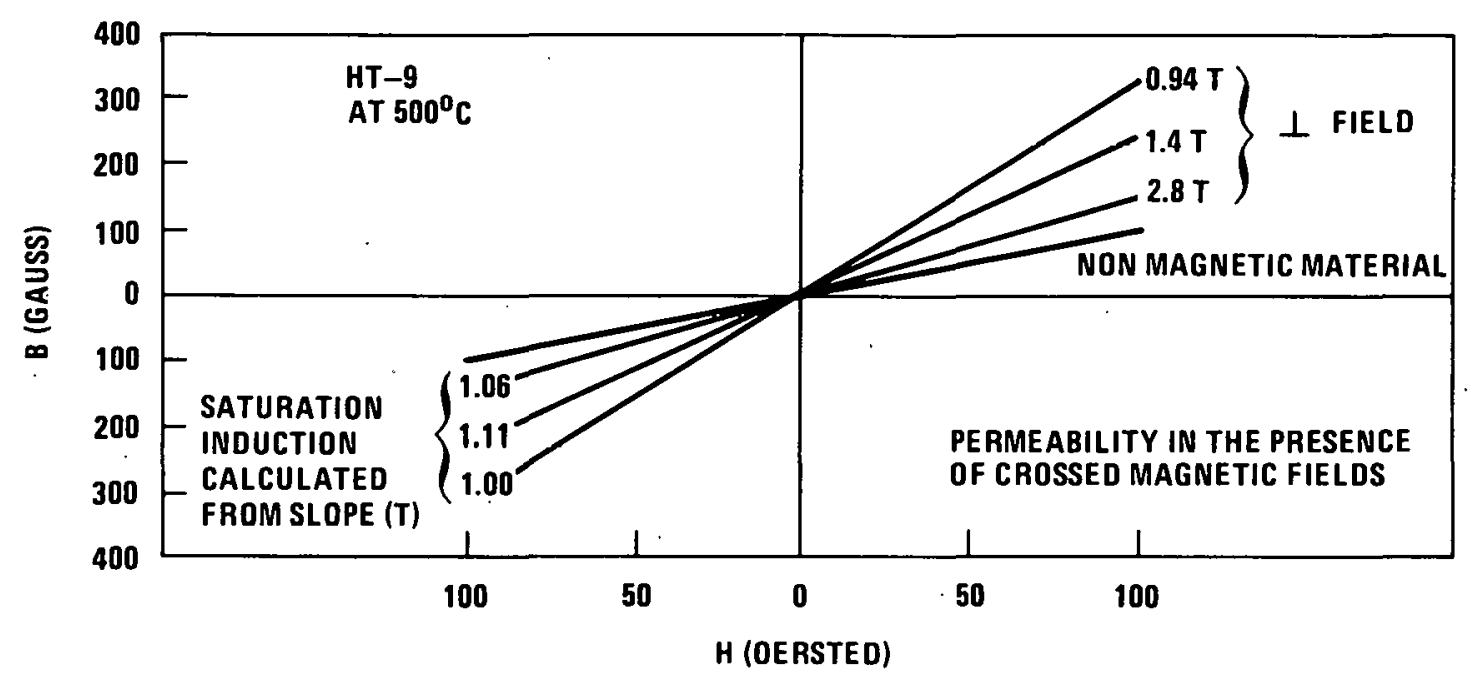

Fig. 4-5. Magnetic properties in a simulated tokamak environment

in a field of 20,000 oersted with a saturation induction of 10,000 gauss, the permeability, instead of being 1.50, which is its value for a bias field parallel to the axis, now has an apparent value of 1.62 . In Fig. 4-5, the saturation inductance has been calculated by an iterative technique from the apparent slope of the $B$ vs $H$ line and the results are consistent with the value of $\mathrm{B}_{\mathrm{S}}$ found from the normal hysteresis loop with no bias.

In the case of the coil with the symmetry axis perpendicular to the bias field, part of the torus is parallel to the bias field and part is perpendicular. In this case, the $B$ vs $H$ line approached unity more rapidly as the bias field was increased. This is to be expected since at 40,000 oersted, part of the torus has an effective permeability of unity and part a value of 1.25. Unfortunately, no quantitative data was obtained at very large fields because the primary circuit opened up before calibrated photographs were obtained.

\subsection{CONCLUSIONS}

For 9 to $12 \%$ Cr martensitic stainless steels under reactor conditions where the wall temperature is expected to be about $500^{\circ} \mathrm{C}$ and the steady 
state toroidal field about 40,000 gauss, the saturation induction is about 11,000 to 13,000 gauss. This means that the permeability as far as pololdal field coils are concerned is less than 1.33. In Section 5, it is shown that this requires only minor modifications in reactor design and operations.

There are, however, two additional complications. The poloidal field coils cannot be tested with the toroidal field coils off. Secondly, during startup, the value of the saturation induction will be somewhat larger until the walls reach operating temperature. This is not a major concern, but it should be taken into account in the plans for achieving ignition.

\section{REFERENCES}

4-1 ROSENWASSER, S. N., MILLER, P., DALESSANDRO, J. A., RAWLS, J. M., TOFFOLO, W. E. and CHEN, W., "The Application of Martensitic Stainless Steels in Long Lifetime Fusion First Wall/Blankets," First Topical Meeting on Fusion Reactor Materials, Miami Beach, Florida, January 29-30, 1979, General Atomic Company Report GA-A15356.

4-2 CHEN, W. Y., PEURON, U. A., MILLER, P. H., Jr., RAWLS, J. M. and ROSENWASSER, S. N., Paper 34-04, 8th Symposium on Engineering Problems of Fusion Research, San Francisco, Nov. 13-16, 1979, "Magnetic Aspects of Martensitic Stainless Steels on Structural Materials for Tokamak Reactors," General Atomic Report GA-A15619, October 1979.

4-3 PRAEG, W. nF., Paper 4302, 8th Symposium on Engineering Problems of Fusion Research, San Francisco, Nov. 13-16, 1979, Magnetization Hysteresis and Eddy Current Shielding of $9 \% \mathrm{Cr}$ Stainless Steel as a Function nf Temperature.

4-4 The terminology used follows the definitions in ASTM Specification A127, with the exception that in the 2nd paragraph of Section 4.2, $B_{O}$ is used instead of $\mathrm{H}$. 


\section{SYSTEMS QUESTIONS}

Martensitic 9-12\% chromium steels may offer significant advantages as a first wall/blanket material in terms of greater wall lifetime in comparison with commonly considered materials such as $20 \mathrm{CW} 316$ (Ref. 5-1). However, it is important to evaluate the magnetics impact of a ferromagnetic blanket in a tokamak reactor. Studies reported here have focused on two potential problem areas: the effects on plasma performance and the impact on the mechanical design of the blanket. A 3-D field code IRON allowing the presence of saturable ferromagnetic material was used for the investigation.

One major concern in the area of plasma performance is the effect of the ferromagnetic blanket on toroidal field ripple. The code IRON described in Section 5.1 was utilized extensively to analyze the toroidal field ripple of tokamak reactors with axisymmetric ferromagnetic (FM) blankets. The reactors considered have sizes and configurations corresponding to TNS (Ref. 5-2), ETF (Ref. 5-3), and STARFIRE (Ref. 5-4). The additional effects created by blanket penetrations such as neutral beam ducts were also studied.

Another concern is the interaction of the ferromagnetic blanket with the plasma shaping and control system, in particular the field-shaping colls. The code IRON was used to study the poloidal field configuration in the presence of a toroidal field, which tends to put the FM blankets into a high level of saturation. The perturbations to the poloidal fields introduced by the FM blankets were computed, and the implications on the required compensations in the poloidal field controls are discussed. The possible time delay in pololdal field control caused by the presence of the fM blankets was also studied.

The most important question from the point of view of engineering Impact appears to be the magnet1c forces on the blankel. The magnetic 
forces on blanket sections of different geometries were analyzed using the code IRON, which was benchmarked by comparison with analytic calculations for axisymmetric geometries. The implications of the resultant forces on the mechanical design of the blanket are discussed.

\subsection{DESCRIPTION OF NUMERICAL TOOLS}

The 3-D saturable iron field code IRON was developed based on a numerical formulation very similar to that utilized in the field code GFUN3D developed by the Rutherford Laboratory (Ref. 5-5). However, IRON was not designed for the generality GFUN3D was implemented for, so a considerably simplified coil geometry was assumed, In the present version, only a set. of toroldal coils and a set of axisymmetric poloidal coils are considered. The second simplification is in the manner in which the shapes of the ferromagnetic elements are specified. Analytic expressions are used to specify the three-dimensional boundary surfaces of the ferromagnetic elements. Typically the surfaces are of cylindrical, spherical or ellipsoidal shapes and the bodies may be further separated into smaller, usually periodic structures, by means of planes. A large number of insulating gaps may be defined by means of pairs of cutting planes. Such a scheme can most effectively take into account the inherent toroidal and poloidal symmetries of the reastor genmetries.

The field $\vec{H}$ and magnetization $\vec{M}$ are solved based on an integral equation scheme similar to GFUN3D. The scalar potential $\phi_{\mathrm{m}}$ is given by

$$
\phi_{\mathrm{m}}=\frac{1}{4 \pi} \int \frac{\overrightarrow{\mathrm{M}} \cdot \overrightarrow{\mathrm{r}}}{\mathrm{r}^{3}} \mathrm{dV},
$$

and the field due to the magnetized body is

$$
\overrightarrow{\mathrm{H}}_{\mathrm{m}}=-\vec{\nabla} \phi_{\mathrm{m}}
$$


The total field is the sum of the field due to the current flow $\overrightarrow{\mathrm{H}}_{c}$ and $\overrightarrow{\mathrm{H}}_{\mathrm{m}}$

$$
\overrightarrow{\mathrm{H}}=\overrightarrow{\mathrm{H}}_{\mathrm{c}}+\overrightarrow{\mathrm{H}}_{\mathrm{m}}
$$

Furthermore, the magnetization $\vec{M}$ is related to $\vec{H}$ by

$$
\overrightarrow{\mathrm{M}}=\chi \overrightarrow{\mathrm{H}}
$$

The numerical scheme involves subdividing the FM region into subelements (denoted by Greek indices $\alpha, \beta, \ldots$ ) each assigned a constant magnetization $\vec{M}_{\alpha}$. The subdivision should be sufficiently fine so that discretizing errors are minimized, while keeping the number of sub-elements below a limit so that computation time does not become excessive. If $\overrightarrow{\mathrm{H}}_{\alpha}$ and $\overrightarrow{\mathrm{H}}_{\mathrm{c} \alpha}$ are the total field and the field due to coil currents at the center of sub-element $\alpha$, respectively, then for the case with $\mathrm{N}$ sub-elements, -

$$
\begin{aligned}
& \overrightarrow{\mathrm{H}}_{\alpha}=\overrightarrow{\mathrm{H}}_{c \alpha}+\sum_{\alpha=1}^{\mathrm{N}} \stackrel{\mathrm{C}}{\alpha \beta}_{\beta} \cdot \overrightarrow{\mathrm{M}}_{\beta} \\
& =\mathrm{H}_{\mathrm{c} \alpha}+\sum_{\beta=1}^{\mathrm{N}} \mathrm{x}_{\beta} \overleftrightarrow{\mathrm{C}}_{\alpha \beta} \cdot \overrightarrow{\mathrm{H}}_{\beta} \text {. }
\end{aligned}
$$

The compuneuls of the demagnetization tensor $\overleftrightarrow{\mathrm{C}}_{\alpha \beta}$ are given by

$$
\begin{aligned}
c_{\alpha \beta, i j} & =\frac{1}{4 \pi} \int_{v_{\beta}}\left[3\left(x_{\alpha i}-x_{\beta i}^{\prime}\right)\left(x_{\alpha j}-x_{\beta j}^{\prime}\right) r^{-5}\right. \\
& \left.-\delta_{i j} r^{-3}-\frac{4}{3} \pi \delta_{i j} \delta\left(\vec{x}_{\alpha}-\vec{x}_{\beta}^{\prime}\right)\right] d v_{\beta}^{\prime},
\end{aligned}
$$

where $i, j$ denotes the coordinate indices $(x, y, z)$, and $\delta(\vec{r})$ is the Dirac delta function. Then the problem is reduced to iteratively solving for 
the local field $\vec{H}_{\alpha}$ and susceptibility $\chi_{\alpha}$ from the set of $3 \mathrm{~N}$ equations

$$
\sum_{\beta=1}^{N} \sum_{j=1}^{3} x_{\beta}\left(c_{\alpha \beta, i j}-\delta_{i j} \delta_{\alpha \beta}\right) H_{\beta, j}=H_{c \alpha, i}
$$

As compared with GFUN3D in which the basic sub-elements are tetrahedral in shape, in IRON the sub-elements are defined by cutting the FM region with planes perpendicular to the rectangular conrdinate axie. In the optional case where cylindrical coordinates are used, the boundaries of sub-elements are simply constant $r, z$ or $\theta$ surfaces. The numerical computation of the demagnetization tensor $\overleftrightarrow{C}_{\alpha \beta}$ is simply a summation of Eq. (5-6) over a number of lattice points, and the integrand is a simple power expression free of the singularity and multivaluedness problems which plague the analytically integrated expressions for the demagnetization tensor of tetrahedral sub-elements (Ref. 5-5). Notice that the singularity in Eq. (5-6) when the field point and source point coincide can be easily cut off because the integration of the first two terms of the integrand in Eq. (5-6) yields zero when the field point is situated at the geometric center of a restangular cube. It was discovered that for a finite sized element, such a numerical scheme converges rapidly because the integrand behaves as $r^{-3}$, such an approach also avoids the difficulty in implementing the analytical integration scheme for tetrahedral elements which requires a large number of coordinate transformations.

The accuracy of IRON was checked against analytical computations for simple geometries such as a simple ferromagnetic sphere in a uniform external field. In general, the agreement was quite satisfactory. Accuracy to within a fruction of a perceill call le dulleved cypically with about bU sub-elements. The fact that most of the cases studied involved highly saturated FM elements implies fairly rapid convergence in the iteration. Typically less than five iterations were required to achieve the desired accuracy. The inherent toroidal symmetry also helps greatly in reducing the amount of computation time needed to solve the problem. 


\subsection{MAGNETIC PERTURBATIONS - TOROIDAL FIELD}

Toroidal field ripple computations were based on reactor geometries representing three conceptual designs denoted as GA TNS, ETF and STARFIRE. The characteristic parameters most relevant in this context are given in Table 5-1. The blanket material was assumed to have a saturation magnetization of $1 \mathrm{~T}$, as shown in the experimental results described in Section 4. This is reached when the ambient field is above $2 \mathrm{~T}$, which is the case for all three examples.

Figure 5-1 is a plot of the midplane toroidal field ripple as a function of radius for STARFIRE, for the three cases: (1) non-magnetic blanket, (2) axisymmetric FM blanket, and (3) FM blanket with $0.5 \mathrm{~m} \times 0.5 \mathrm{~m}$ penetration. It can be seen that the axisymmetric FM blanket causes insignificant modification to the field ripple. Even for the case with penetration, the ripple over the plasma region is very modest. Similar results were obtained for studies made on the GA TNS and ETF. Thus it can be concluded that due to the high level of saturation, the FM blankets have effective permeability close to unity, and therefore do not cause any significant changes to the toroidal fleld ripple.

TABLE $5-1$

PARAMETERS USED FOR FIELD PERTURBATION AND FORCE COMPUTATIONS

\begin{tabular}{l|c|c|c}
\hline & GA TNS & FTF & STARFIRE \\
\hline Plasma major radius, $\mathrm{R}(\mathrm{m})$ & 3.6 & 5.0 & 6.92 \\
Plasma current (MA) & 11.4 & 5 & 13.5 \\
Number of TF-coils & 12 & 12 & 12 \\
Total TF ampere turns (MA) & 90 & 132 & 183 \\
Blanket thickness (m) & 1 & 1 & 1.3 \\
Outer blanket inside radius (m) & 4.6 & 7.1 & 8.4 \\
Outer blanket outside radius (m) & 5.6 & 8.1 & 9.7 \\
Inner blanket inside radius & -- & 2.8 & 4.5 \\
Inner blanket outside radius & -- & 3.0 & 4.9 \\
\hline
\end{tabular}




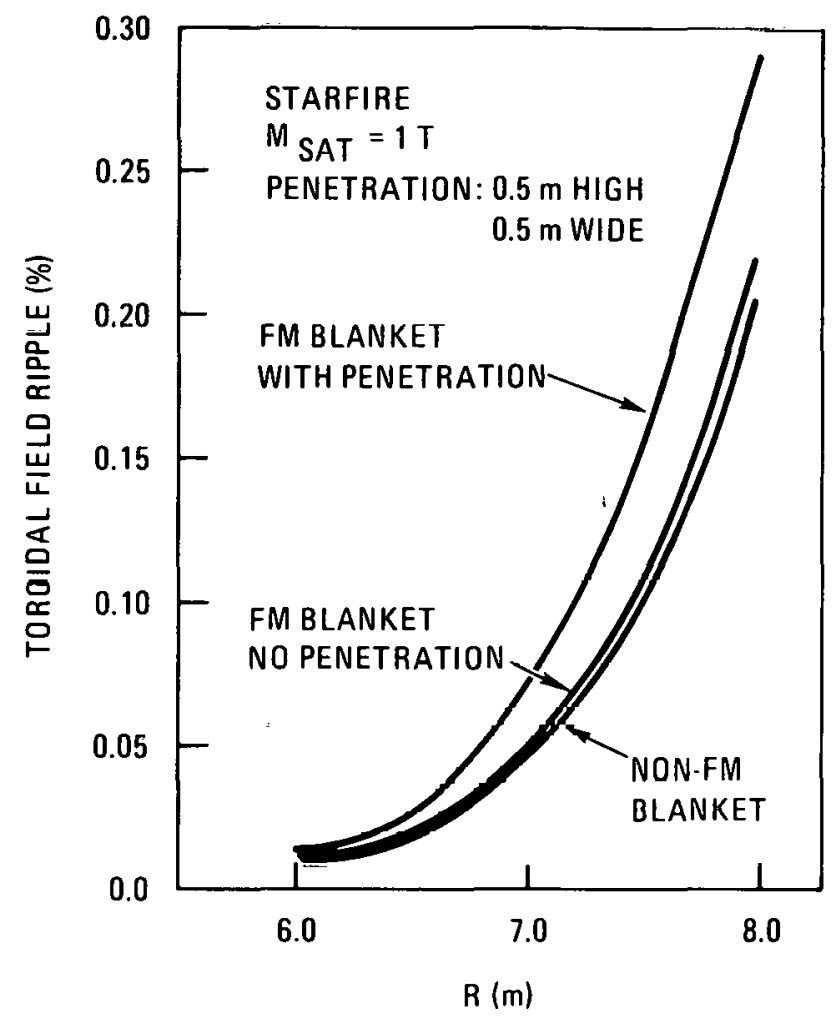

Fig. 5-1. STARFIRE toroidal field ripple showing the effects of a ferromagnetic (FM) blanket with and without penetrations

\subsection{MAGNETIC PERTURBATIONS - POLOIDAL FIELD}

The perturbations in the poloidal fields introduced by the FM blankets have been studied by comparing the poloidal field distributions for the same poloidal current distribution with and without the FM blankets. Because the currents in the poloidal system are much smaller than those of the toroidal system and act on a more open magnetic circuit, the poloidal magnetization cannot change the permeability significantly. This means the parametric coupling between the two systems is very small. Furthermore, it is clear from energy considerations that the permeability reached when building up the final state of currents is independent of the order in which the poloidal and toroidal currents are built up. This is due to the fact that hysteresis effects are negligible at the high level of saturation that the final toroidal currents generate. All of these expectations were verified 
during the course of the computational studies. While hysteresis effects were not modeled, it is clear that the hysteresis loop normally traversed by the high magnetic field will likely be so small as to be entirely undetectable.

Figure 5-2 is the plot of poloidal field perturbation as a function of the $z$-coordinate for various radii in the plasma region for STARFIRE. It can be seen that throughout the plasma region field perturbations as high as $3 \%$ can be generated by the presence of the FM blankets. However, since in practice all the poloidal coils are actively controlled for the stability and position control of the plasma, such a small perturbation can be easily countered by adjustment of the control parameters.

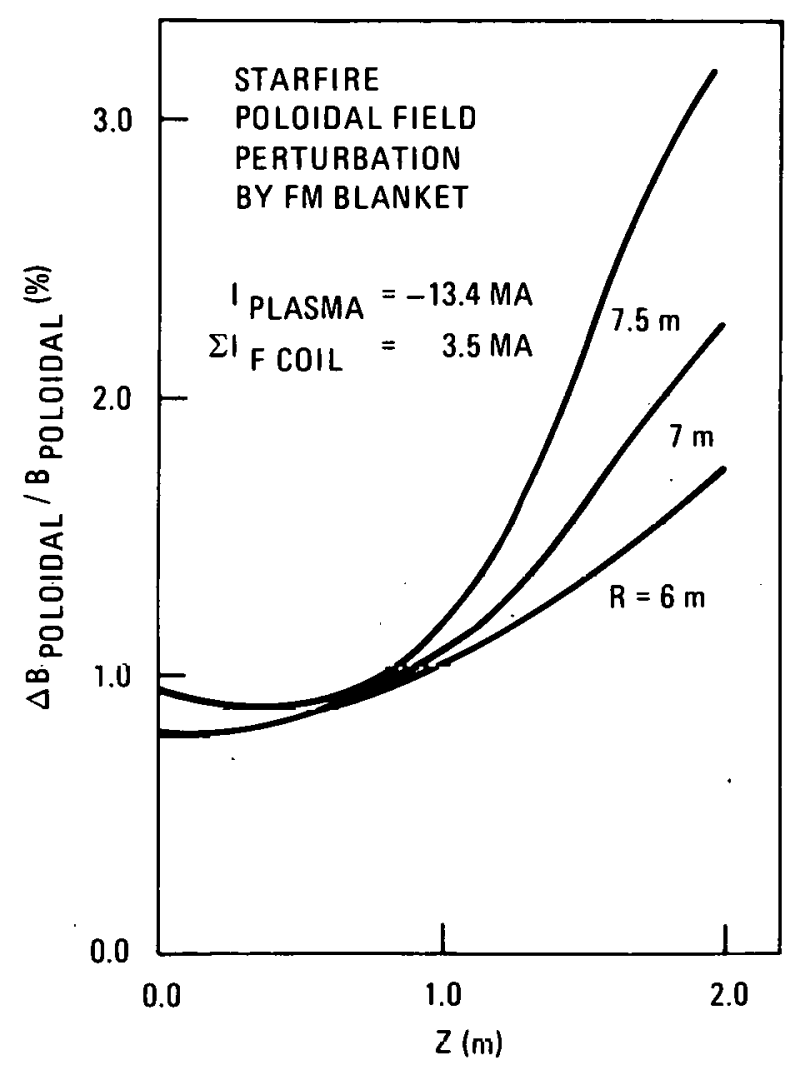

Fig. 5-2. STARFIRE poloidal fleld perturbation due to a ferromagnetic blanket 


\subsection{MAGNETIC PERTURBATIONS - TRANSIENT ANALYSIS}

Several types of transient flux excursions are influenced by the presence of the magnetized blanket. The following events can be considered as the most important operational transients that could eventually be analyzed with sufficient detail with a suitable computational model:

1. Ohmic heating by means of rapidly changing currents in an $\mathrm{OH}-\mathrm{coil}$ system.

2. Plasma control by means of controlled current excursions in a set nf field control coile.

3. Plasma interruption.

As the details of the blanket, especially the shape and degree of subdivision, are not known at this time, we present here only a few broad inferences drawn from basic principles and from transient analyses with a highly idealizod model.

Generally speaking, we need now to be concerned only about those relative changes in the transient behavior that are caused by the presence of a sufficiently subdivided magnetic structure. It is assumed from the outset that subdivision into essentially insulated parts will be necessary for any type of metallic blanket, ferromagnetic or not.

In general, the subdivision of the conducting material in electromagnetic power equipment is carried so far that the significant dimension, namely the one which is perpendicular to the direction of the magnetic flux, is roughly of the order of the skin depth at the appropriate frequency. Thus copper busbars in $60 \mathrm{~Hz}$ power apparatus are about $5.5 \mathrm{~mm}$ thick and steel laminations in transformers about $0.5 \mathrm{~mm}$ thick. For pulsed power applications, the thickness can be larger if adequate cooling or heat sinking is provided. In this context, it may be useful to get an idea of what the skin depth is 
for magnetically saturated materials at frequencies that roughly correspond to typical plasma interruption ramp times (assumed to be equal to one quarter of the period):

Interruption time

Approximate equivalent frequency

Skin depth for $\rho=96 \mu \Omega \mathrm{cm}$

$\begin{array}{ll}100 \mu \mathrm{s} & 1000 \mu \mathrm{s} \\ 2500 \mathrm{~Hz} & 250 \mathrm{~Hz} \\ 0.01 \mathrm{~m} & 0.03 \mathrm{~m}\end{array}$

The relative permeability $\mu_{r}$ used in this calculation $\left[\delta=\left(2 \rho / \mu_{r} \mu_{0} \omega\right)^{-1 / 2}\right]$ was 1.2 , in agreement with the measured values reported in Section 4 , but its exact value is of very little significance here considering the much larger uncertainty in the equivalent frequency and the details of the geometry.

Eddy current effects in cylindrical blankets can be modeled by means of two skin coils, one on each surface of the blanket. If the blanket has one or more radial cuts, their effect is taken into account by specifying a negative number of turns $(-1)$ to one of the coils. Multiple gaps only increase the resistance of the skin-deep current paths.

The applicability of employing the skin depth in this manner has been shown for instance by the successful use of this approach in magneformer design. Further justification is found from the fact that the results are very insensitive to the length of the ramp time.

To estimate the reduction of inductance due to skin effect, the solution of a simplified diffusion equation which describes the penetration of flux into magnetic material was integrated.

To get an idea on how far the effective permeability is actually reduced under transient conditions, we assume an equivalent sinusoidal applied field so that the concept of skin depth can be used. Furthermore, we assume that the blanket is an infinitely long slab of thickness $2 \mathrm{~b}$. The we11-known steady state distribution (Ref. 5-6) of the flux is, when $x$ is measured from the vertical center plane, 


$$
B=B_{o} \frac{\cosh [(1+j)(x / \sqrt{2 \delta})]}{\cosh [(1+j)(b / \sqrt{2 \delta})]} .
$$

With $u \equiv(b / \sqrt{2 \delta})$ the total flux is

$$
\phi=\int_{-b}^{b} B d x=2 B_{o} \delta\left[\left(\sin ^{2} u+\sinh ^{2} u\right) /\left(\cos ^{2} u+\sinh ^{2} u\right)\right]^{1 / 2}
$$

Since the dc-flux would be $\phi_{0}=2 b B_{0}$ the flux reduction factor due to variable field on the surface is

$$
\frac{\phi}{\phi_{0}}=\frac{\delta}{b}\left[\left(\sin ^{2} u+\sinh ^{2} u\right) /\left(\cos ^{2} u+\sinh ^{2} u\right)\right]^{1 / 2}
$$

The maximum change in the inductance of the coil most affected, namely an equivalent field control coil, was obtained this way. It is equivalent to the actual set of field coils in the sense that it creates the same vertical field at the major radius. Then a transient analysis of an equivalent circuit was carried out using an eigenvector method which gives the semi-analytically computed time-history of the poloidal field at selected points in the plasma region.

The same transient analysis carried out with unaffected inductance values and the difference between the poloidal field magnitudes was calculated as a percentage of the total poloidal field.

It turns out from the integrated solution of the magnetic diffusion equation that the inductance changes only a few percent for a ramp time of $1 \mathrm{~ms}$. It depends on the ratio of the cross-sectional area of the blanket and the poloidal flux area within the entire F-coil. Typical values are about $2 \%$ for ETF and STARFIRE and about twice that much for GA TNS, which has only half as much coil area. The final outcome of these and other approximate calculations is that the additional perturbations and time 
delays caused by the magnetization of the blanket are small enough not to warrant more accurate analysis. The problems are much the same as if the blanket was nonmagnetic. A few percent increase in time delays or magnitudes is of the same order of magnitude or smaller than the combined errors in model, data and analysis.

\subsection{MAGNETIC LOADS}

The analysis of stationary and transient body forces was limited in most cases to simple cylindrical structures. Two methods were used, both of which utilized the Maxwell stress tensor. An option in the IRON program permits the computation of all force components in a body of somewhat arbitrary but analytically definable shape through numerical integration over a loosely fitting surface that encloses the magnetic body. A simpler analytical method (Appendix A) gives the radial body force and the equivalent external pressure over an infinitely long cylindrical shell. The methods generally agree (for sufficiently long cylinders) within 15-25\%. The simple analytical method always gives the higher values. Since the numerical method is much more time consuming, the results that are given in Table 5-2 have been computed analytically. Thus the forces are somewhat on the pessimistic side.

The table shows that the static pressures amount to only a few atmospheres. Since the forces are directed towards the axis, it should be possible to design the blanket modules so that a self-supporting "keystoned" structure is achieved. 'l'he wedge-shaped modules will be under compression. Even in the case of an ellipsoidal blanket this should be possible. The STARFIRE design was also analyzed with the IRON program with a mostly ellipsoldal shell and it was found that the average radial body-force density (without the inner wall) amounts to $1.4 \times 10^{6} \mathrm{n} / \mathrm{m}^{3}$ for $\mathrm{M}=1 \mathrm{~T}$, in agreement be expected from the analytical results.

Figure 5-3 shows a series of analytically computed equivalent magnetic pressures as a function of magnetization times packing factor. This product was chosen as the argument because in the reactor blanket, which serves both 
TABLE ${ }^{\circ} 5-2$

RADIAL BODY FJROES AND EQUIVALENT INWARD PRESSURES

AI TWO VALUES OF $\mathrm{M}^{*}$

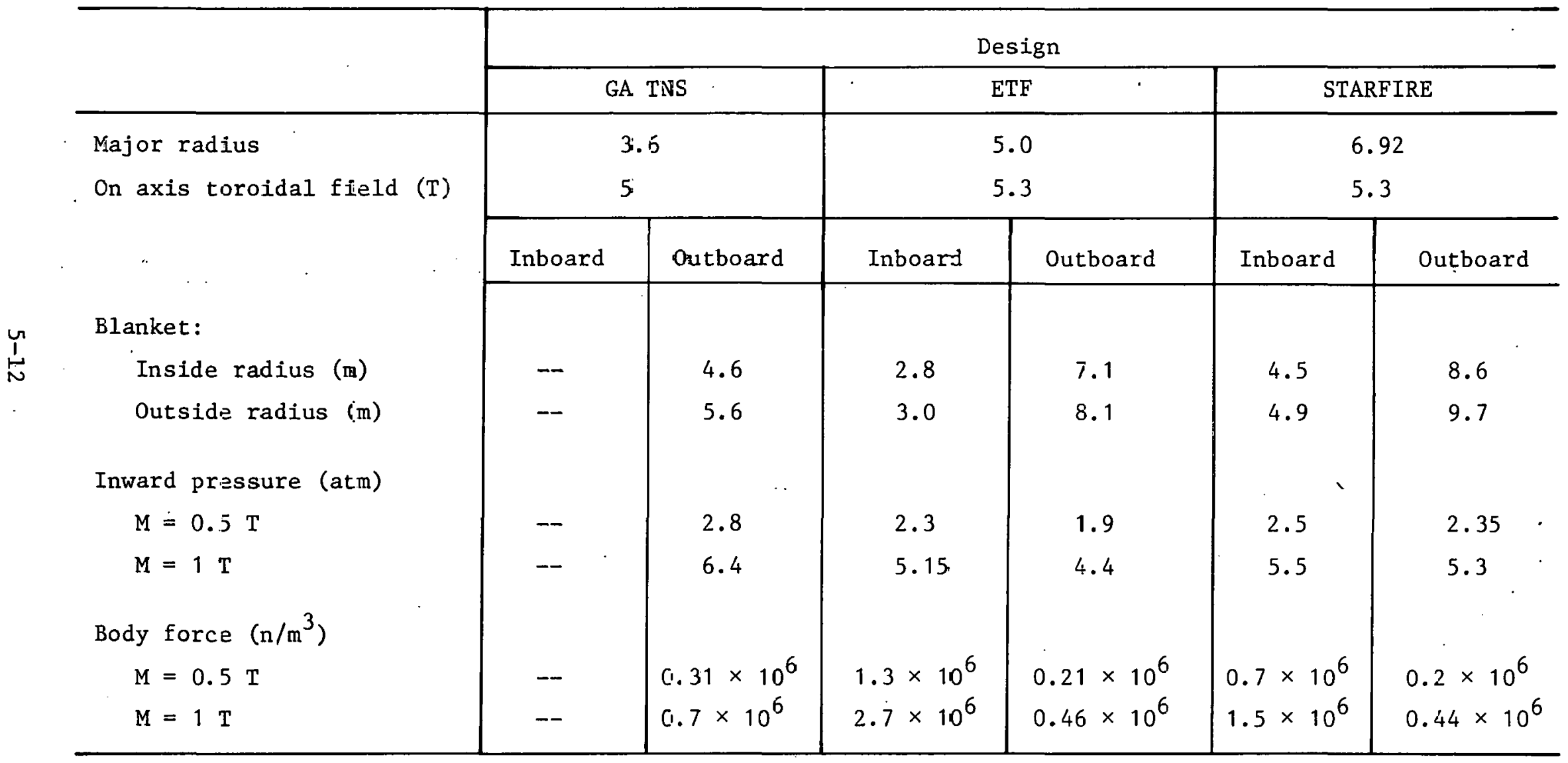

\footnotetext{
${ }^{*} \mathrm{M}$ = saturation magnetization times packing factor.
} 


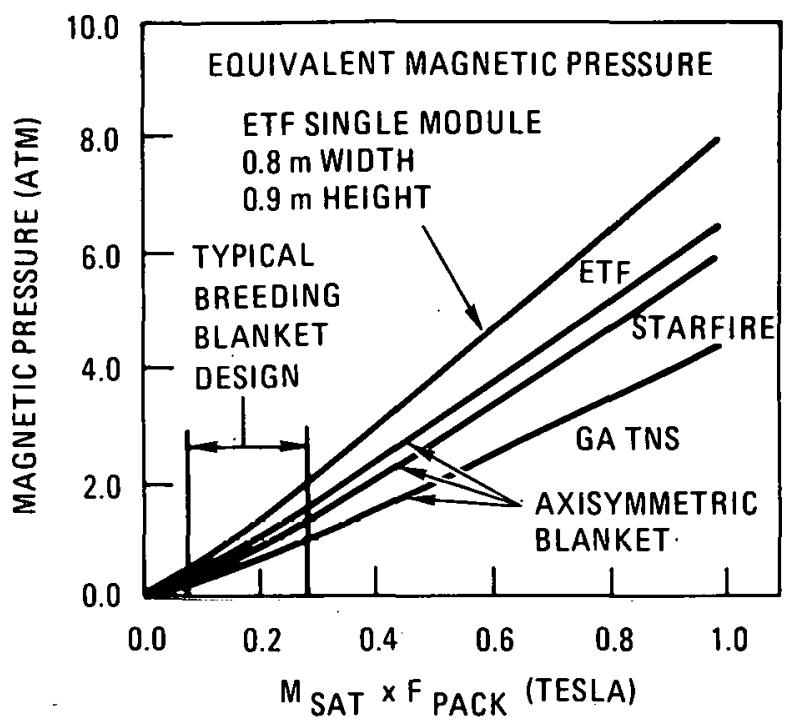

Fig. 5-3. Magnetic loading on the ferromagnetic blankets for the GA TNS, STARFIRE and ETF designs

for breeding and energy conversion, a large fraction of the volume is occupied by the breeding materials and coolant flow channels, and the FM material only occupies typically $10-20 \%$ of the volume. The low packing factor effectively reduces the magnetic loading on the blanket.

With regard to the transient loads generated on the blankets due to plasma disruption, a FM blanket should behave almost the same as a non-FM blanket.

\subsection{SAFETY AND ENVIRONMENTAL CONSIDERATIONS}

The radioactivity and biological hazard potentials (BHP) for ferritic steel-structured blankets are important for maintenance and environmental safety considerations. The afterheat of the blanket is a crucial parameter both for blanket operation after shutdown and in the case of a loss of coolant flow accident. In order to estimate these parameters quantitatively, several neutronics calculations have been performed using the one-dimensional transport code, ANISN (Ref. 5-7), with $\mathrm{P}_{3} \mathrm{~S}_{6}$ approximations, in cylindrical geometry. 
The blanket model adopted consists of a $10 \mathrm{~mm}$ first wa11, a tritium breeding zone and a graphite reflector. The breeding zone is composed of $10 \%$ structure and $90 \% \mathrm{Li}_{2} \mathrm{O}$ by volume. The 1 ithium breeding compound, $\mathrm{Li}_{2} \mathrm{O}$, is assumed to be $80 \%$ dense to account for the packing effect. In the neutron flux calculation, the breeding zone thickness is $0.25 \mathrm{~m}$ which is adequate to generate a total tritium breeding ratio in excess of unity. The results for the blanket with HT-9 and 316 SS as structural material are 1.19 and 1.17 , respectively. Hence HT-9 does have a modest advantage in terms of breeding efficiency.

'l'he tluxes so obtained are then used as input to the fusion radioactivity calculated code DKR (Ref. 5-8). The results are shown in Tables 5-3, 5-4 and 5-5 for radioactivity, BHP and afterheat, respectively, and in each instance the results for 316 SS are exhibited for comparison with HT-9. A standard operational scenario is adopted for purposes of comparison, specifically, continuous operation for 6 years with a neutron wall loading of $1 \mathrm{MW} / \mathrm{m}^{2}$, followed by shutdown. As seen in Table 5-3, the radioactivity in the HT-9structured blanket at shutdown is about 1.17 curies per watt (thermal), which is about $10 \%$ lower than in the 316 ss-structured blanket. At 100 years after shutdown, it is about $1.8 \times 10^{-5}$ curies per watt, which is more than a factor of 2 lower than in the $316 \mathrm{ss}$-based blanket.

\section{TABLE 5-3}

RADIOACTIVITY AFTER SHUTDOWN IN HT-9 AND 316 SS-BASED BLANKETS (ASSUME $1 \mathrm{MW} / \mathrm{m}^{2}$ WALL LOADING FOR 6 YEARS)

\begin{tabular}{|c|c|c|}
\hline \multirow{2}{*}{$\begin{array}{l}\text { TIME AFTER } \\
\text { SHUTDOWN }\end{array}$} & \multicolumn{2}{|c|}{ STRUCTURAL MATERIAI } \\
\hline & 316 SS & HT -9 \\
\hline 0 & 1.31 & 1.1 .7 \\
\hline I DAY & $7.8 \times 10^{-1}$ & $6.6 \times 10^{-1}$ \\
\hline 1 MONTH & $6.6 \times 10^{-1}$ & $5.9 \times 10^{-1}$ \\
\hline 1 YEAR & $3.7 \times 10^{-1}$ & $4.0 \times 10^{-1}$ \\
\hline 100 YEARS & $4.3 \times 10^{-5}$ & $1.8 \times 10^{-5}$ \\
\hline
\end{tabular}


TABLE 5-4

BIOLOGICAL HAZARD POTENTIAL AFTER SHUTDOWN IN HT-9 AND 316 SS-STRUCTURED BLANKETS (ASSUME $1 \mathrm{MW} / \mathrm{m}^{2}$ WALL LOADING FOR 6 YEARS)

\begin{tabular}{l|cc}
\hline \multirow{2}{*}{$\begin{array}{l}\text { TIME AFTER } \\
\text { SHUTDOWN }\end{array}$} & \multicolumn{2}{|c}{ STRUCTURAL } \\
\cline { 2 - 3 } & $316 \mathrm{SS}$ & $\mathrm{HT}-9$ \\
\hline 0 & $6.7 \times 10^{2}$ & $3.2 \times 10^{2}$ \\
$1 \mathrm{D} A \mathrm{Y}$ & $4.1 \times 10^{2}$ & $2.5 \times 10^{2}$ \\
$1 \mathrm{YEAR}$ & $9.7 \times 10^{1}$ & $5.2 \times 10^{1}$ \\
100 YEARS & $4.3 \times 10^{-1}$ & $2.1 \times 10^{-2}$ \\
\hline$*$ UNITS: $\mathrm{km}^{3}$ OF AIR $/ \mathrm{kW}$
\end{tabular}

TABLE $5-5$

AFTERHEAT FOLLOWING SHUTDOWN IN HT-9 AND 316 SS-BASED BLANKETS

\begin{tabular}{|c|c|c|}
\hline \multirow{2}{*}{$\begin{array}{l}\text { TIME AFTER } \\
\text { SHUTDOWN }\end{array}$} & \multicolumn{2}{|c|}{ STRUCTURAL MATERIAL ${ }^{*}$} \\
\hline & $316 \mathrm{SS}$ & $\mathrm{HT}-9$ \\
\hline 0 & 1.4 & 1.3 \\
\hline 1 DAY & $1.5 \times 10^{-1}$ & $5.9 \times 10^{-2}$ \\
\hline $1 \mathrm{MONTH}$ & $1.3 \times 10^{-1}$ & $5.4 \times 10^{-2}$ \\
\hline 1 YEAR & $4.7 \times 10^{-2}$ & $3.0 \times 10^{-2}$ \\
\hline
\end{tabular}

This trend also affects the biological hazard potential. It is about $3.2 \times 10^{2} \mathrm{~km}^{3}$ of air $/ \mathrm{kW}_{\text {th }}$ at shutdown and decreases to about $5.2 \times 10^{1}$ and $2.1 \times 10^{-2} \mathrm{~km}^{3}$ of air $/ \mathrm{kW}_{\text {th }} 1$ year and 100 years after shutdown, respectively, for the HT-9-structured blankets. As illustrated in Table 5-4, the biological hazard potential for the 316 SS-based blankets is about a factor of 2 higher than that in the HT-9-based blankets. 
As seen from Table 5-5, the afterheat at shutdown for HT-9 and 316 SSbased blankets are about the same, 1.3 percent of total operating power. However, at one day after shutdown, it drops to about $5.9 \times 10^{-2}$ and $1.5 \times 10^{-1}$ percent of operating power for HT-9 and 316 ss-based blankets, respectively. The afterheat for the HT-9 blanket maintains a lower level than that of the 316 SS blanket thereafter.

From the above discussion, we may conclude that the post-irradiation effects for the HT-9-based blanket, i.e., the amount of after-shutdown radioactivity, BHP and afterheat, are smaller than for the 316 SS-based blanket. From these points of view, HT-9. alloy is a preferable choice of structural material than 316 SS for fusion applications.

\section{REFERENCES}

5-1 ROSENWASSER, S. N., et al., "The Application of Martensitic Stainless Steels in Long Lifetime Fusion First Wa11/Blanket," paper presented at the First Topical Meeting on Fusion Reactor Materials, Bal Harbour, Florida $(19 / 9)$.

5-2 "GA INS Project, Status Report for FY-78," General Atomic Report GA-A15100, Vo1. V (1978).

5-3 SAGER, P. H., "Design Considerations for the Fusion Engineering Test Facility," paper to be presented at this conference.

5-4 BAKER, C. C., et al., "STARFIRE - Commerical Tokamak Power Plant Overview," paper to be presented at this conference.

5-5 ARMSTRONG, A., et a1,, "New Developments in the Magnet Design Computer Program GFUN3D," Proc. 5th Int1. Conf. on Magnet Technology, Rome, Italy, April 1975.

5-6 GREENWOOD, A., "Electrical Transients in Power Systems," WileyInterscience (1971).

5-7 ENGLE, W. W., Jr., "Uses Manual for ANISN," Report No. K-1693, Oak Ridge Gaseous Diffusion Print (1967).

5-8 SUNG, T. Y. and VOGELSANG, F., "DKR: A Radioactivity Calculation Code for Fusion Reactors," Report No. UWFDM-170, Nuclear Engineering Dept., University of Wisconsin (1976). 

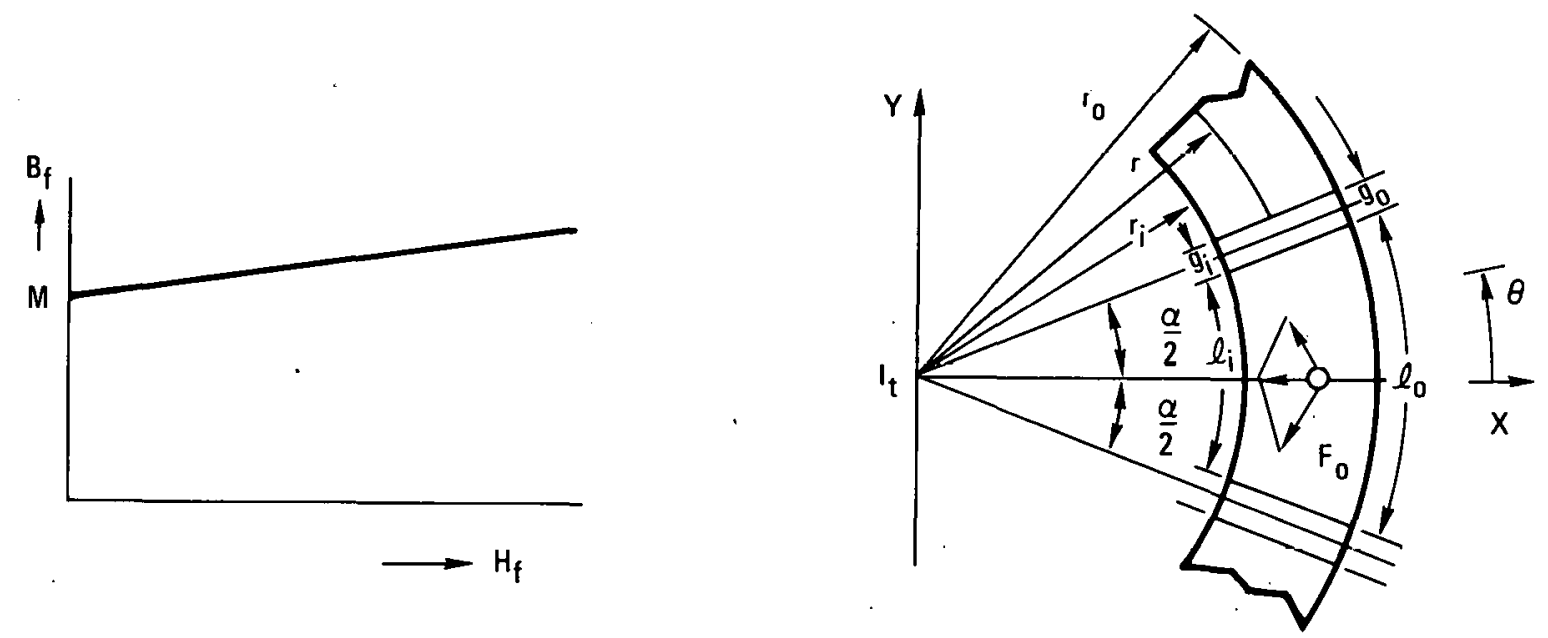

Consider a long cylindrical gapped blanket magnetized in the azimuthal direction by a large number of toroidal field coils or by a single currentcarrying concentric rod with symmetric return paths. The resulting vacuum field is given by

$$
H_{0}=\frac{I_{T}}{2 \pi r}
$$

We assume that the toroidal current $I_{T}$ is large enough so that the blanket saturates and we can use the simple linear expression

$$
B_{f}=M+\mu_{o} H_{f}
$$

for the magnetization curve. In typical fusion confinement systems the effective saturation magnetization $M$ would be of the order of 1 tesla or 
less for a martensitic stainless steel and the induction $B_{f}$ is larger than 3 tesla. Equation A-2 can be written

$$
H_{f}=\left(B_{E}-M\right) / \mu_{O}
$$

Neglecting the fringing flux and applying Ampere's Law $\mathrm{I}_{\mathrm{T}}=\int \mathrm{Hds}$ so the magnetic circuit around a blanket which contains $\mathrm{n}$ identical sectors and insulating gaps of length $g$ we have, for any $r$ between $r_{i}$ and $r_{0}$

$$
I_{T}=\mathrm{ngH}_{g}+\mathrm{nl}_{\hat{f}} \mathrm{II}_{\overline{\mathrm{f}}}
$$

or, per ocetor:

$$
I_{g} \equiv \frac{I_{T}}{n}=g H_{g}+\ell_{f} H_{f}=g H_{g}+\ell_{f} \frac{B_{f}-M}{I_{o}} \text {, }
$$

therefore:

$$
H_{g}=\frac{I_{g}+\ell_{f} M / \mu_{0}}{g+\ell_{f}} \text {, }
$$

where $\ell_{f}=(2 \pi r-n g) / n$ is the length of the flux path in any "iron" sector. Furthermore we apply the usual continuity of field condition on the curved surfaces: $H_{\theta}=H_{f}, r=r_{i}$ or $r=r_{0}$. Continuity of flux, on the other hand, requires that $B_{f}=\mu_{0} H_{g}$ across the boundaries of the air gaps. With Eq. A-2 substituted, this gives

$$
\mathrm{H}_{\theta}=\mathrm{H}_{\mathrm{f}}=\mathrm{H}_{\mathrm{g}}-\frac{\mathrm{M}}{\mu_{\mathrm{o}}}
$$

Equations $A-4$ and $A-5$ give the necessary field values for the evnluation of forces when using the Maxwell tensor approach. The forces due to magnetization are obtained most conveniently by calculating a surface integral of Maxwell stresses over any closed surface that contains only the magnetized body in question. 
The normal and tangential components. of the Maxwell stresses, considered as tractions per unit area, are

$$
\begin{aligned}
& t_{n}=0.5 \mu_{0}\left(H_{n}^{2}-H_{t}^{2}\right) \\
& t_{t}=\mu_{0} H_{n} H_{t} .
\end{aligned}
$$

We consider first the outer and inner curved surfaces $r=r_{0}$ and $r=r_{i}$. Here $t_{n} \equiv t_{r}, t_{l} \equiv t_{\theta}=0, H_{n} \equiv H_{r}=0$ and $H_{t} \equiv H_{\theta}=H_{f}=H_{g}-M / \mu_{0}$. The $x$ directed components of the radial force per unit axial length are

$$
\begin{aligned}
& F_{x_{0}}^{\prime}=-0.5 \mu_{0} \int_{-\alpha / 2}^{\alpha / 2} H_{\theta_{0}}^{2} \cos \theta r_{0} d \theta=-\mu_{0} H_{\theta_{0}}^{2} r_{0} \sin \frac{\alpha}{2} \\
& F_{x_{i}}^{\prime}=0.5 \mu_{0} \int_{-\alpha / 2}^{\alpha / 2} H_{i}^{2} \cos \theta r_{i} d \theta=0.5 \mu_{0} H_{\theta_{i}}^{2} r_{i} \sin \frac{\alpha}{2} .
\end{aligned}
$$

The net $\mathrm{x}$-force due to these components is

$$
\mathrm{F}_{\mathrm{x}}^{\prime}=\mathrm{F}_{\mathrm{x}_{i}}+\mathrm{F}_{\mathrm{x}_{0}}=\mu_{0} \sin \frac{\alpha}{2}\left[\mathrm{r}_{i} \mathrm{H}_{\theta_{i}}^{2}-\mathrm{r}_{0} \mathrm{H}_{\theta_{0}}^{2}\right] \text {, }
$$

where

$$
\begin{gathered}
H_{\theta_{i}}=H_{f_{i}}=H_{g_{i}}-\frac{M}{\mu_{0}}=\frac{I_{g}+\ell_{i} M / \mu_{u}}{g_{i}+l_{i}}-\frac{M}{\mu_{0}} \\
H_{\theta_{0}}=H_{f_{0}}=H_{g_{0}}-\frac{M}{\mu_{0}}=\frac{I_{g}+\left(r_{0} / r_{i}\right) \ell_{i} M / \mu_{0}}{\left(r_{0} / r_{i}\right)\left(g_{i}+l_{i}\right)},
\end{gathered}
$$

This conforms with the notion of a hydrostatic pressure acting perpendicularly to the flux lines. According to the same point of view, there is also a Eension acting along the flux lines. The forces due to this tension will be calculated next. 
An azimuthally directed force $\mathrm{F}_{\theta}$ acts on each gap surface and gives rise to a radially directed net force $\mathrm{F}_{\mathrm{x}}^{\prime \prime}=0.2 \mathrm{~F}_{\theta} \sin (\alpha / 2)$. The magnitude of $\mathrm{F}_{\theta}$ is obtained by integrating the normal Maxwell stress $t_{n}=0.5 \mu_{0} H_{g}^{2}$ from $r_{i}$ to $r_{0}$, hence

$$
F_{x}^{\prime \prime}=-2 \sin (\alpha / 2) \int_{r_{i}}^{r_{i}}\left[\frac{I_{g}+\left(r / r_{i}\right) l_{i} M / \mu_{0}}{\left(r / r_{i}\right)\left(g_{i}+l_{i}\right)}\right]^{2} d r .
$$

The net $x$-directed force $F_{x}=F_{x}^{\prime}+F_{x}^{\prime \prime}$ which we assume to act at the centroid of the rigid sectur is, after the evaluation. of the Inlegral

$$
\begin{aligned}
F_{x}= & \frac{\mu_{0} \sin (\alpha / 2)}{\left(g_{i}+\ell_{i}\right)^{2}}\left\{r_{0}\left(\frac{r_{i}}{r_{0}} I_{g}+\ell_{i} M / \mu_{0}\right)^{2}-r_{i}\left(I_{g}+l_{i} M / \mu_{0}\right)^{2}\right. \\
& \left.+\left[I_{g}^{2} r_{i}^{2}\left(\frac{1}{r_{i}}-\frac{1}{r_{0}}\right)+\left(2 I_{g} r_{i} l_{i} M / \mu_{0}\right) \ln \frac{r_{e}}{r_{i}}+\left(r_{0}-r_{i}\right)\left(\frac{l_{1} M}{\mu_{0}}\right)^{2}\right]\right\} .
\end{aligned}
$$

This force is computed per unit axial length of the cylindrical blanket (or shield) sector. The net body force per unit volume or an equivalent external hydrostatic pressure may be more illustrative. The result for the body force per unit volume is

$$
f_{b}=\frac{2 \mu_{o} I_{g}^{2} \sin (\alpha / 2) r_{i} / \ell_{i}}{\pi\left(r_{o}^{2}-r_{i}^{2}\right)}\left(\frac{r_{i}}{r_{o}}-1-\frac{\ell_{i} M}{\mu_{o} I_{g}} \ln \frac{r_{0}}{r_{i}}\right),
$$

and the equivalent external pressure is given by

$$
p_{e}=\frac{\mu_{0} I_{g}^{2} r_{i} / r_{0}}{2 \pi l_{i}}\left[\frac{r_{i}}{r_{0}}-1-\frac{\ell_{i} M}{\mu_{0} I_{g}} \ln \frac{r_{0}}{r_{i}}\right] \text {. }
$$

